University of Wollongong

Research Online

Australian Institute for Innovative Materials -

Papers

Australian Institute for Innovative Materials

$1-1-2018$

\title{
A 3D conductive scaffold with lithiophilic modification for stable lithium metal batteries
}

\author{
Rensheng Song \\ Harbin Institute of Technology \\ Bo Wang \\ Harbin Institute of Technology \\ Ying Xie \\ Heilongjiang University \\ Tingting Ruan \\ Harbin Institute of Technology \\ Fei Wang \\ Harbin Institute of Technology
}

See next page for additional authors

Follow this and additional works at: https://ro.uow.edu.au/aiimpapers

Part of the Engineering Commons, and the Physical Sciences and Mathematics Commons

Research Online is the open access institutional repository for the University of Wollongong. For further information contact the UOW Library: research-pubs@uow.edu.au 


\title{
A 3D conductive scaffold with lithiophilic modification for stable lithium metal batteries
}

\author{
Abstract \\ In this study, a non-lithiophilic nickel foam (NF) was transformed into a 3D lithiophilic N-doped graphene/ \\ nickel foam (NGNF) scaffold by a simple hydrothermal method. This scaffold can increase the area for $\mathrm{Li}$ \\ deposition, improve the poor lithiophilicity of NF, and decrease the overpotential for Li deposition, leading \\ to uniform Li plating/stripping. Thus, the average coulombic efficiency for Li deposition on the NGNF \\ electrode can remain as high as $98.3 \%$ over 200 cycles and $98.0 \%$ over 100 cycles at current densities of \\ $2 \mathrm{~mA} \mathrm{~cm}$-2and $4 \mathrm{~mA} \mathrm{~cm}-2$, respectively. Even when the Li deposition capacity is increased to as high as \\ $10 \mathrm{~mA} \mathrm{~h} \mathrm{cm-2,} \mathrm{the} \mathrm{cells} \mathrm{with} \mathrm{NGNF} \mathrm{electrodes} \mathrm{still} \mathrm{exhibit} \mathrm{stable} \mathrm{cycling} \mathrm{performance} \mathrm{with} \mathrm{a} \mathrm{high}$ \\ coulombic efficiency of $98.9 \%$ after 84 cycles. Density functional theory (DFT) calculations were \\ performed to achieve a deeper understanding of the interaction between $\mathrm{Li}$ atoms and the designed \\ scaffold. In addition, the potential application of the scaffold is further demonstrated by the superior \\ electrochemical performance of an assembled LiFePO4/Li-NGNF full cell under room-temperature and \\ low-temperature conditions.

\section{Disciplines} \\ Engineering | Physical Sciences and Mathematics

\section{Publication Details} \\ Song, R., Wang, B., Xie, Y., Ruan, T., Wang, F., Yuan, Y., Wang, D. \& Dou, S. (2018). A 3D conductive scaffold \\ with lithiophilic modification for stable lithium metal batteries. Journal of Materials Chemistry A, 6 (37), \\ 17967-17976.
}

\section{Authors}

Rensheng Song, Bo Wang, Ying Xie, Tingting Ruan, Fei Wang, Ye Yuan, Dianlong Wang, and Shi Xue Dou 


\section{WILEY-VCH}

DOI: $10.1002 /(($ please add manuscript number $))$

\section{Article type: Full Paper}

\section{A 3D conductive scaffold with lithiophilic modification for stable lithium metal batteries}

Rensheng Song, Bo Wang*, Ying Xie*, Tingting Ruan, Fei Wang, Ye Yuan, Dianlong Wang* and Shixue Dou*

R. S. Song, Dr. B. Wang, T. Ruan, F. Wang, Y. Yuan, Prof. D. L. Wang MIIT Key Laboratory of Critical Materials Technology for New Energy Conversion and Storage, School of Chemistry and Chemical Engineering, Harbin Institute of Technology, 150001 Harbin, China.

School of Materials Science and Engineering, Harbin Institute of Technology, 150001 Harbin, China

E-mail: wangbo19880804@163.com (B. Wang)

E-mail: wangdianlonghit@163.com (D. L. Wang)

Prof. Y. Xie

School of Materials Science and Engineering, Harbin Institute of Technology, 150001 Harbin, China.

E-mail: xieying@hlju.edu.cn (Y.Xie)

Prof. S. X. Dou

Institute for Superconducting \& Electronic Materials, Australian Institute of Innovative Materials, University of Wollongong, Wollongong, NSW 2500, Australia E-mail: shi_dou@uow.edu.au (S.X. Dou)

Keywords: nickel foam, N-doped graphene, Li plating/stripping, Coulombic efficiency, electrochemical performance

In this work, non-lithiophilic nickel foam (NF) is transformed into 3D lithiophilic N-doped graphene/nickel foam (NGNF) scaffold by a simple hydrothermal method, which could increase the area for Li deposition, improve the poor lithiophilicity of NF, and decrease the overpotential for Li deposition, leading to uniform Li plating/stripping. Thus, the Coulombic efficiency for Li deposition on NGNF electrode can remain as high as $98.3 \%$ over 200 cycles 


\section{WILEY-VCH}

at a current density of $2 \mathrm{~mA} \mathrm{~cm}-2$ with a total capacity of $1 \mathrm{mAh} \mathrm{cm}^{-2}$. Even when the $\mathrm{Li}$ deposition capacity is increased to as high as $10 \mathrm{mAh} \mathrm{cm}^{-2}$, the cells with NGNF electrode still can exhibit stable cycling performance with high Coulombic efficiency of $98.1 \%$ after 75 cycles. Density functional theory (DFT) calculations are introduced to achieve a deeper understanding of the interaction between $\mathrm{Li}$ atoms and the designed scaffold. In addition, the potential application is further demonstrated by the superior electrochemical performance of an assembled $\mathrm{LiFePO}_{4} / \mathrm{Li}$-NGNF full cell under room-temperature and low-temperature conditions.

\section{Introduction}

Based on the insertion-host graphite anode, there is only limited space for further increasing the energy density of the Li-ion battery. ${ }^{[1]}$ Therefore, the development of a high-energy anode is required for next-generation battery applications. Li metal, featuring the highest specific capacity (3860 mAh g$\left.{ }^{-1}\right)$, the most negative reduction potential (-3.04 V vs. standard hydrogen electrode), and the lowest density among anode materials $\left(0.59 \mathrm{~g} \mathrm{~cm}^{-3}\right)$, is referred to as the ultimate choice for Li batteries. ${ }^{[2]}$ Despite so many attractive features, the commercial application of Li metal anode is still far away. This is because some key issues are still not effectively resolved, such as the safety problems induced by Li dendrites, low Coulombic efficiency, and short life. These problems have been widely believed to result from the immediate reaction of highly reactive $\mathrm{Li}$ with non-aqueous electrolyte, causing uncontrolled $\mathrm{Li}$ dendrite growth, unstable and inhomogeneous solid electrolyte interphase (SEI) film, and "dead Li” during the Li plating/stripping process ${ }^{[3]}$ More seriously, Li dendrites will penetrate the 


\section{WILEY-VCH}

membrane to come into direct contact with the cathode, resulting in internal short circuits in the cell, thermal runaway, and even fire hazard or explosion. Unstable SEI film and "dead Li" will consume Li irreversibly and decrease the Coulombic efficiency of cells. In addition, the above problems are aggravated by the unlimited volume change in the plating/stripping process owing to the hostless nature of $\mathrm{Li}$, which leads to a broken SEI film and "fresh Li" that is exposed to the electrolyte.

To deal with these issues, many efforts have been made to suppress Li dendrites and stabilize Li plating/stripping. In terms of the electrolyte, the use of various additives is an easy and effective way to obtain a stable and uniform SEI film, ${ }^{[4]}$ which is helpful to reduce the defects in the SEI film and prevent the growth of Li dendrites. In order to resolve the selfamplifying growth behavior of $\mathrm{Li}$ dendrites during repeated cycles of Li metal anode, a novel self-healing electrostatic shield mechanism is proposed to achieve a dendrite-free $\mathrm{Li}$ anode by adding alkali metal ions. ${ }^{[5]}$ This is because some alkali metal ions (such as $\mathrm{Cs}^{+}$and $\mathrm{Rb}^{+}$) have a lower reduction potential than that of $\mathrm{Li}$ ions at low concentration according to the Nernst equation, which could force the further deposition of $\mathrm{Li}$ ions to adjacent regions of protuberant tips through the positively charged electrostatic shield. To a certain extent, electrolyte additives are an effective way to inhibit the growth of Li dendrites. The process for the in-situ formation of SEI film is immediate and uncontrolled, however, and it is still very difficult to understand the complete composition of the SEI film. Another approach is to decorate the Li metal surface with an artificial and robust SEI layer before assembly into a cell, and its accurate composition can be obtained and adjusted according to the original design. Actually, these artificial SEI layers, such as from $\mathrm{Li}_{3} \mathrm{~N},{ }^{[6]} \mathrm{Li}_{3} \mathrm{PO}_{4},{ }^{[7]} \mathrm{Cu}_{3} \mathrm{~N}+$ styrene butadiene rubber $(\mathrm{SBR}),{ }^{[8]}$ and 


\section{WILEY-VCH}

polydimethylsiloxane (PDMS) ${ }^{[9]}$ have been confirmed to have a positive effect towards suppressing the formation of $\mathrm{Li}$ dendrites and improving the Coulombic efficiency of $\mathrm{Li}$ deposition. Nevertheless, regardless of whether there is an in-situ SEI film or an ex-situ SEI film, most of them are still unable to accommodate the serious volume changes in Li metal anode, especially under high current density and high areal capacity. Recently, a threedimensional (3D) porous anode scaffold, with high surface area and plenty of inner empty space, has been designed to decrease the effective current density of Li metal and minimize its huge volume changes by the melt infusion of $\mathrm{Li}$, which is helpful to stabilize the structure of SEI film and inhibit Li dendrite growth during long cycling. ${ }^{[10]}$ Although Li composite electrodes based on the 3D scaffold can play a certain role in preventing Li dendrites, the melt-infusion method requires the high temperature and extremely low water and oxygen concentration conditions.

Herein, in this work, a 3D lithiophilic N-doped graphene/nickel foam (NGNF) scaffold produced by a simple hydrothermal method has been designed to host Li. Compared to other types of 3D matrix that have only been applied in the laboratory research stage, nickel foam (NF) is a mature commercial product and easy to acquire, which has already been widely used in the nickel-metal hydride battery field. Although NF with high surface area could decrease the effective current density of the electrode, it is very easy to form severe Li dendrites owing to its high Li nucleation overpotential ${ }^{[11]}$ and the "tip effect" of protruding defects. ${ }^{[12]}$ Our research is also inspired by the research of Zhang and coworkers, who used N-doped graphene (NG) to coat the surface of two-dimensional (2D) planar $\mathrm{Cu}$ current collector, regulating the initial $\mathrm{Li}$ nucleation and growth process due to its beneficial N-based functional groups. ${ }^{[13]}$ 


\section{WILEY-VCH}

Therefore, we intended to design a 3D lithiophilic matrix by combining the advantages of 3D NF and lithiophilic NG. Based on this viewpoint, a NGNF composite was prepared by a facile hydrothermal method in this work. According to the density functional theory (DFT) calculations, we found that strong interactions exist between $\mathrm{Li}$ and pyridine and pyrrole $\mathrm{N}$, as well as pyridine-N oxide species. The prepared NGNF scaffold has the following features: (1) Good electronic conductivity, which is beneficial for plating/stripping of Li and decreases the polarization of the electrode. (2) Large surface area, which is helpful to decrease the effective current density of the electrode, prolonging Sand's time according to the widely accepted Chazalviel model. ${ }^{[14]}$ (3) Strong lithiophilic action owing to NG, which is beneficial for reducing Li nucleation overpotential and plating Li uniformly. (4) Capability of storing a certain amount of $\mathrm{Li}$ via intercalation of $\mathrm{Li}$ ions into $\mathrm{NG}$, which could contribute some $\mathrm{Li}$ storage capacity to the whole electrode. (5) Open porous structure, which can accommodate the Li deposition, alleviating the huge volumetric changes during the plating/stripping process of $\mathrm{Li}$ metal anode. Li anode with this 3D lithiophilic scaffold was assembled with Li foil counter electrode, and the resulting cells could maintain a high Coulombic efficiency of $98.3 \%$ after 200 cycles at a current density of $2 \mathrm{~mA} \mathrm{~cm}{ }^{-2}$. In addition, when paired with $\mathrm{LiFePO}_{4}$ (LFP) cathode, the LFP/Li-NGNF full cell delivered a high reversible capacity of $94.1 \mathrm{mAh} \mathrm{g}^{-1}$ after 500 cycles, which is obviously higher than that of 3D NF (49.5 mAh g ${ }^{-1}$ after 400 cycles) and 2D bare $\mathrm{Cu}$ electrode (30 $\mathrm{mAh} \mathrm{g}^{-1}$ after only 75 cycles). Moreover, the LFP/Li-NGNF full cell also exhibits good low-temperature electrochemical performance.

\section{Results and discussion}




\section{WILEY-VCH}

Scheme 1 illustrates the nucleation and deposition process as well as the micromorphology of metallic $\mathrm{Li}$ on 2D Cu foil, 3D NF, and 3D NGNF electrode. Owing to the rough surface of the microstructure for 2D Cu foil, the current distribution on its surface is inhomogeneous, resulting in the isolated and random Li nucleation. Subsequently, more and more Li ions preferentially deposit on the existing $\mathrm{Li}$ nuclei. It should be noted that, because of the relatively small surface area of the 2D planar structured $\mathrm{Cu}$ foil, the effective current density of the electrode is quite high, which further shortens the Sand's time for dendrite growth. ${ }^{[15]}$ Compared with 2D Cu foil, 3D NF with much larger surface area could significantly decrease the effective current density of the electrode, leading to a higher value of Sand's time. The overpotential for Li nucleation on its surface is very high, however, because Ni metal is not lithiophilic, which is unfavorable for homogeneous Li deposition. ${ }^{[11]}$ Thus, Li dendrites still tend to occur on the protuberance defects of the 3D scaffold surface due to the "tip effect". In contrast, NG with lithiophilic functional groups has a positive effect towards guiding uniform $\mathrm{Li}$ nucleation and growth, which has been confirmed by Zhang and coworkers. ${ }^{[13]}$ Nevertheless, NG as a Li storage matrix has only reported for a coating on conventional 2D planar $\mathrm{Cu}$ foil until now, which limits its potential application in high-performance Li metal batteries, especially under the condition of high current density and high capacity. Therefore, we propose a 3D porous NGNF scaffold with abundant lithiophilic groups as the Li plating matrix, which makes the binding ability of the $\mathrm{Li}$ atoms with the scaffold much stronger, leading to uniform Li distribution and growth during the charge and discharge process.

Figure 1a-c shows the surface morphology of bare $\mathrm{Cu}, \mathrm{NF}$, and NGNF before Li nucleation, respectively. The insets in the upper right corners are the corresponding digital 


\section{WILEY-VCH}

photographs of the different electrode scaffolds. As shown in Figure 1a, the surface of Cu foil is quite rough from microscopic point of view, which is unfavorable for uniform Li distribution. According to the images of Figure 1b and Figure 1c, it can be seen that the color of NF changed from silver gray to black, indicating that NF was infilled with and uniformly coated by NG. The Raman spectrum of the NGNF in Figure S2 in the Supporting Information exhibits two characteristic bands of graphene, which are located at around 1345 and $1595 \mathrm{~cm}^{-1}$, corresponding to the D and G bands, respectively. ${ }^{[16]}$ To investigate the surface chemical composition of NGNF, energy dispersive spectroscopy (EDS) and X-ray photoelectron spectroscopy (XPS) measurements were conducted. According to the EDS results, the scope of $\mathrm{N}$ mapping is well consistent with the elemental distribution of $\mathrm{C}$, indicating that the $\mathrm{N}$ element is homogeneously distributed throughout the graphene skeleton (Figure 1d-f). As shown in Figure 1g, an additional composite $\mathrm{N}$ 1s peak is detected for the NGNF composite, which indicates that $\mathrm{N}$ species were successfully introduced through the facile hydrothermal process. The $\mathrm{N}$ 1s peak can be further divided into four components, as displayed in the inset of Figure 1g, including pyridinic $\mathrm{N}(398.8 \mathrm{eV})$, pyrrolic $\mathrm{N}(400.1 \mathrm{eV})$, quaternary $\mathrm{N}(401.9 \mathrm{eV})$, and pyridine-N oxides $(405.1 \mathrm{eV})$, respectively. ${ }^{[17]}$ By comparing the areas of the above four deconvoluted peaks, it can be found that the main components of the $\mathrm{N}$ dopant are pyridinic $\mathrm{N}$, pyrrolic $\mathrm{N}$, and pyridine- $\mathrm{N}$ oxides, which take up more than $98 \%$ of the total $\mathrm{N}$ content.

According to density functional theory (DFT) calculations, the stronger binding energy with $\mathrm{Li}$ atoms for pyridinic $\mathrm{N}$, pyrrolic $\mathrm{N}$, and pyridine- $\mathrm{N}$ oxides can be confirmed, as shown in Figure 2. Because the adsorption of $\mathrm{Li}$ on the $\mathrm{Ni}$ or $\mathrm{Cu}(001)$ surface is relatively weak, $\mathrm{Li}$ ions have a strong tendency to aggregate near protuberances of an uneven metal surface, where 


\section{WILEY-VCH}

there is greater field strength. As a result, Li dendrites will appear during repeated cycling. Such a phenomenon can also be found on an ideal graphene surface, since the adsorption energy is only $-1.46 \mathrm{eV}$, which is even weaker than those of $\mathrm{Cu}(-2.34 \mathrm{eV})$ and $\mathrm{Ni}(-2.86 \mathrm{eV})$. If there are no defects on the graphene surface, Li dendrites can also be expected. (The optimized structure of Li adsorbed on defect-free graphene is shown in Figure S1.) However, our calculations further suggest that when $\mathrm{N}$ is doped into the lattice of graphene and forms the pyridine $\mathrm{N}$, pyrrole $\mathrm{N}$, and pyridine- $\mathrm{N}$ oxide structures, the adsorption energy of Li will be improved significantly. The above results clearly suggest that the stronger interactions between $\mathrm{Li}$ and the pyridine $\mathrm{N}(-4.89 \mathrm{eV})$, pyrrole $\mathrm{N}(-3.22 \mathrm{eV})$, and pyridine- $\mathrm{N}$ oxide structures $(-3.46 \mathrm{eV})$ are helpful for trapping $\mathrm{Li}$ within the local area, thus leading to the uniform dispersion of nucleation sites on the scaffold surface. ${ }^{[18]}$ Therefore, it is reasonable to believe that these lithiophilic functional groups can guide a uniform Li distribution on the NGNF through the strong interactions between them.

As we expected, the scanning electron microscopy (SEM) result validates that NG does have a positive role in guiding $\mathrm{Li}$ to nucleate and grow uniformly on the $3 \mathrm{D}$ substrate. Compared with the non-uniform Li deposition observed for both $\mathrm{Cu}$ foil and NF, a uniform $\mathrm{Li}$ deposition is obtained for NGNF. When the Li deposition is controlled at $0.5 \mathrm{~mA} \mathrm{~cm}^{-2}$ with a capacity of $0.5 \mathrm{mAh} \mathrm{cm}^{-2}$, there are obvious differences in surface morphology among $\mathrm{Cu}, \mathrm{NF}$, and NGNF electrode. As shown in the SEM images of Figure 3a-c, the Li distribution is quite uneven with irregular $\mathrm{Li}$ dendrite on $\mathrm{Cu}$ electrode, which suggests that $\mathrm{Cu}$ electrode has relatively weak binding interaction with $\mathrm{Li}$ atoms, leading to obvious growth of $\mathrm{Li}$ dendritez. Although NF could decrease the effective current density owing to its 3D porous structure, the 


\section{WILEY-VCH}

plated Li on NF only partly covers the exposed surface of NF (Figure 3d-f), and a high energy barrier still exists for metallic Li nucleation. (This will be further discussed in the following section.) Compared to the weak binding between NF and $\mathrm{Li}$, the interaction between NGNF and $\mathrm{Li}$ is stronger, owing to the lithiophilic functional groups of NG (as shown in Figure $\mathbf{2 b}$ ). Therefore, a surface with uniform Li nucleation is obtained for the NGNF, which confirms that NGNF has an effective role in suppressing Li dendrites.

It is noteworthy that the uniform Li metal nucleation as seeds in NFNG will be beneficial for further Li deposition, because the following Li deposition preferentially takes place on the existing Li metallic sites. ${ }^{[15]}$ Therefore, when the Li metal deposition is further increased to the charge capacity of $1 \mathrm{mAh} \mathrm{cm}^{-2}$, the problems of uneven Li distribution and Li dendrites are intensified for both $\mathrm{Cu}$ and NF. In contrast, due to the stronger interaction between the lithiophilic functional groups of NG and $\mathrm{Li}$ atoms, the NGNF scaffold still can achieve relatively uniform Li deposition (Figure S3). Meanwhile, it is obvious that Li dendrites can't be completely avoided for NGNF, and a small amount of aggregated Li dendrite still exists around the protruding tips. There are two possible reasons for this phenomenon: on the one hand, although NF has been uniformly infilled and wrapped by NG as much as possible, it is still hard to acquire an absolute uniformity of Li deposition owing to the "tip effect" of electric field derived from the surface protuberance areas. On the other hand, NG with lithiophilic functional groups is beneficial for uniform Li nucleation and initial growth, but it does not mean that these groups still have a strong enough interaction for further homogeneous Li deposition. This is because once NG with lithiophilic functional groups has already been covered by a Li metal layer, the subsequent $\mathrm{Li}$ deposition is based on the interaction between existing Li metal 


\section{WILEY-VCH}

and the forthcoming Li atoms. Therefore, the "tip effect" of electric field derived from surface protuberances means that it is possible to generate irregular Li aggregates or $\mathrm{Li}$ dendrites, especially at high current density and high charge capacity. In general, based on the SEM results and the above discussion, it could be concluded that the NGNF has an effective role in guiding uniform Li deposition and inhibiting Li dendrites.

The lithiophilic property of NGNF can be further reflected by comparing the nucleation overpotential of Li metal deposition on the surfaces of 2D Cu foil, 3D NF, and 3D NGNF electrode at different current densities. The nucleation overpotential of Li metal is defined as the difference between the sharp tip voltage and the later flat voltage plateau. ${ }^{[11]}$ As shown in Figure 4a, under a low current density of $0.5 \mathrm{~mA} \mathrm{~cm}{ }^{-2}$, the nucleation overpotential on NF electrode is about $98 \mathrm{mV}$, which is close to the value of $\mathrm{Cu}$ electrode $(104 \mathrm{mV})$. Although the 3D foam structure of NF could decrease the effective current density of the electrode, a high overpotential is still necessary for metallic Li to deposit on the surface of NF because of its poor lithiophilicity, resulting in uneven Li distribution and a significant voltage dip at the beginning of the Li plating process. In contrast, NG with lithiophilic N-containing functional groups has a strong interaction with $\mathrm{Li}$ atoms, leading to a much more smooth voltage dip at the nucleation stage. Thus, the NGNF has the smallest value of nucleation overpotential among them $(36 \mathrm{mV})$. With increasing current density, the nucleation overpotential is also increased for all of them (Figure $\mathbf{4 b}, \mathbf{c}$ ). Compared with the dramatic overpotential increase for NF (171 $\mathrm{mV}$ and $277 \mathrm{mV}$ for $1 \mathrm{~mA} \mathrm{~cm}^{-2}$ and $2 \mathrm{~mA} \mathrm{~cm}^{-2}$, respectively) and $\mathrm{Cu}(164 \mathrm{mV}$ and $219 \mathrm{mV}$ for $1 \mathrm{~mA} \mathrm{~cm}-2$ and $2 \mathrm{~mA} \mathrm{~cm}{ }^{-2}$, respectively), the nucleation overpotential for NGNF is only increased slightly ( $47 \mathrm{mV}$ for $1 \mathrm{~mA} \mathrm{~cm}{ }^{-2}$ and $\left.2 \mathrm{~mA} \mathrm{~cm}^{-2}\right)$, indicating its good lithiophilicity. 


\section{WILEY-VCH}

This is because NGNF could relieve the polarization by decreasing the effective current density, and it has a strong interaction with $\mathrm{Li}$ atoms, so Li atoms only need to overcome a lower energy barrier for Li nucleation than in the cases of $\mathrm{NF}$ and $\mathrm{Cu}$ foil.

The excellent electrochemical performance of NGNF electrode was demonstrated by performing galvanostatic testing using coin cells with NGNF as working electrode and Li foil as the counter electrode. Here, the Coulombic efficiency is defined as charging capacity over the discharging capacity. As shown in Figure 4d, under a constant current density of $0.5 \mathrm{~mA}$ $\mathrm{cm}^{-2}$ and fixed capacity of $1 \mathrm{mAh} \mathrm{cm}^{-2}$, the average Coulombic efficiency of $\mathrm{Cu}$ foil oscillates around $90 \%$ and declines to below $30 \%$ after cycling for only 50 cycles. Even though serious Li dendrite formation is observed for 3D structured NF (Figure S3), cells with NF electrode exhibit obviously better cycling performance than those with $2 \mathrm{D} \mathrm{Cu}$ electrode. In addition, although there is a huge difference between the surface morphology of Li deposition on NF and NGNF, both of them present a stable and high Coulombic efficiency over 200 cycles. (The average value of Coulombic efficiency for NF and NGNF is $98.2 \%$ and $99.0 \%$, respectively.) This should be attributed to their good conductivity and porous 3D structure, which reduces the effective current density of their electrodes.

Generally, according to the widely accepted view, only $\mathrm{Li}$ metal anode without $\mathrm{Li}$ dendrites could achieve high Coulombic efficiency and long life, and it is difficult to explain the good cycling performance of NF with its large number of Li dendrite (Figure S3). In fact, instead of the uncontrolled $\mathrm{Li}$ dendrite growth on 2D Cu electrode, $\mathrm{Li}$ dendrites and "dead Li" tend to grow laterally around protruding tips. (This phenomenon can be observed by disassembling the batteries after the $50^{\text {th }}$ Li plating, as shown in Figure S4a-c.) This is because 


\section{WILEY-VCH}

the electrical insulation provided by the contact between the separator and the protruding tips of the 3D collector forces $\mathrm{Li}$ atoms to deposit around the protruding tips, and the voids and pores provide a large amount of storage space to accommodate Li dendrites and "dead Li", rendering superior cycling stability to cells with $3 \mathrm{D}$ electrodes. This result is in agreement with the report of Yang and coworkers, in which they confirmed that excellent cycling and safety performance still can be achieved if the growth of Li dendrite is restricted to the direction parallel to the separator. ${ }^{[19]}$ On further analysis of the morphology of various substrates after the $50^{\text {th }}$ Li plating and stripping (Figure $\mathbf{S 4 d - i )}$ ), it is found that the $2 \mathrm{D} \mathrm{Cu}$ surface is easily completely covered with a thick "dead Li" layer, which makes it difficult for electrons coming from the $\mathrm{Cu}$ collector to participate in further Li plating/stripping. Therefore, a large amount of "dead Li" is accumulated on the surface of the collector (Figure S4d). Even after the process of $\mathrm{Li}$ stripping, we also find that $\mathrm{Li}$ dendrites remain on the surface of the $2 \mathrm{D} \mathrm{Cu}$ electrode (Figure S4g). For the 3D electrodes, owing to their porous structure and large specific surface area, only part of the electrode is covered with "dead Li" aggregates, and there are still plenty of spaces for further Li plating/stripping. The "dead Li" coverage area for NGNF electrode (Figure S4f) is obviously smaller than that for NF (Figure S4e). Meanwhile, for the 3D electrodes, plated Li metal evolves into agglomerated particles rather than remaining in the original dendrite shape after 50 cycles (Figure $\mathbf{S 4 h}, \mathbf{i}$ ), which is helpful for improving the safety of cells.

More importantly, even with further cycling under the higher current density, the cells with NGNF electrode still can retain their stable cycling properties and exhibit the best electrochemical performance compared to $\mathrm{NF}$ and 2D Cu . The cells with NGNF deliver an 


\section{WILEY-VCH}

average Coulombic efficiency as high as $98.0 \%$ for more than 200 cycles under the current density of $1 \mathrm{~mA} \mathrm{~cm}{ }^{-2}$, while that of NF is $96.4 \%$ for 140 cycles, demonstrating the positive role of NG towards improving Coulombic efficiency with high stability and extending cell life. The good performance of NGNF can be further confirmed by the electrochemical impedance spectroscopy (EIS) analysis carried out on the cells after the $1^{\text {st }}$ plating and stripping, and the corresponding Nyquist plot is shown in Figure S5. The high-frequency and low-frequency semicircles are associated with the solid-electrolyte interphase (SEI) formation on the electrode and the charge transfer process on the electrode-electrolyte interfaces. ${ }^{[20]}$ It can be seen that the NGNF shows a combined resistance (resistance of SEI film and charge transfer resistance) of $\sim 29$ ohms after the $1^{\text {st }}$ plating process, which is much smaller than those of $\mathrm{Cu}$ ( $\sim 56$ ohms) and $\mathrm{NF}$ ( $\sim 52 \mathrm{ohms})$. When the Li metal is stripped from the electrode, the native oxide layer of $\mathrm{Cu}$ foil is exposed on the surface, resulting in a high combined resistance. In contrast, benefiting from the 3D structure of electrode, only small changes have taken place for NF and NGNF after the $1^{\text {st }}$ stripping process, and the NGNF always has the smallest charge transfer resistance among them. Therefore, it is reasonable to believe that NGNF favors a rapid Li stripping/plating process and good electrode stability. Due the benefits of NG with lithiophilic functional groups, even when the current density is increased to $2 \mathrm{~mA} \mathrm{~cm}^{-2}$, the NGNF retains its stable cycling performance with high Coulombic efficiency of $98.3 \%$ after 200 cycles. For bare NF electrode, owing to the capacity loss from dead Li and unwanted side reactions, the Coulombic efficiency quickly drops to less than $90 \%$ after only 50 cycles.

As shown in Figure 5a-c, the cells with $\mathrm{NF}$ and $\mathrm{Cu}$ electrode exhibit large $\mathrm{Li}$ plating/stripping voltage oscillations, which is attributed to their unstable electrode/electrolyte 


\section{WILEY-VCH}

interfaces. In contrast, the cells with NGNF electrode maintain stable voltage-time curves, indicating a stable Li plating/stripping process. The Li plating/stripping performance of NGNF was further investigated with charge/discharge curves, as shown in Figure 5d. The discharge voltage profiles of NGNF are nearly the same beyond the $50^{\text {th }}$ cycle, indicating that there is little irreversible capacity loss during long cycling process. The voltage capacity ranges between 0 and $0.5 \mathrm{~V}\left(\mathrm{vs} . \mathrm{Li}^{+} / \mathrm{Li}\right)$, corresponding to the $\mathrm{Li}$ intercalation into the graphene, ${ }^{[21]}$ which is helpful for increasing the total Li storage capacity of the electrode. Voltage hysteresis is defined as a sum of overpotential for Li stripping and Li plating. ${ }^{[10]}$ The voltage hysteresis of NGNF is always stable and is maintained at $\sim 67 \mathrm{mV}$, which is smaller than that of $\mathrm{NF}(99 \mathrm{mV}$ ) only after 130 cycles, indicating that NG has a positive role in stabilizing the SEI film and decreasing the polarization of Li plating/stripping. In contrast, the $\mathrm{Cu}$ shows large and unstable hysteresis under the current density of $2 \mathrm{~mA} \mathrm{~cm}^{-2}$, which can be attributed to the unstable SEI film on $\mathrm{Cu}$ anode (Figure 5e). In fact, with the help of NG with its lithiophilic functional groups, even when the Li deposition capacity is increased to as high as $10 \mathrm{mAh} \mathrm{cm}^{-2}$, the NGNF still retains its stable cycling performance with high Coulombic efficiency of $98.1 \%$ after 75 cycles (as shown in Figure S6).

To further demonstrate the advantages of NGNF electrode for practical application, a LFP/Li-NGNF full cell was assembled and studied with the Li-NGNF hybrid electrode as the negative electrode and a commercial $\mathrm{LiFePO}_{4}$ (LFP; Likai Co. Ltd., Taiwan) cathode as the positive electrode. The performances of the cells with bare $\mathrm{Cu}$ and $\mathrm{NF}$ were also investigated as control samples in the same way. The LFP/Li-Cu full cell delivered a first discharge capacity of $114.2 \mathrm{mAh} \mathrm{g}^{-1}$ at a current density of $0.5 \mathrm{~mA} \mathrm{~cm}^{-2}$. It should be noted that the current density 


\section{WILEY-VCH}

is calculated by the area of the anode electrode ( $\sim 1.8 \mathrm{C}$ for LFP cathode), and the specific capacity is based on the pure LFP mass. The discharge capacity declined to $59.7 \mathrm{mAh} \mathrm{g}^{-1}$ after only 100 cycles, however, corresponding to capacity retention as low as 52.3\% (Figure S7). In contrast, because there is less $\mathrm{Li}$ loss for 3D anode, the LFP full cells with Li-NF and Li-NGNF anode delivered a high reversible capacity of $122.9 \mathrm{mAh} \mathrm{g}^{-1}$ and $124.1 \mathrm{mAh} \mathrm{g}^{-1}$ after 200 cycles, respectively, indicating that the 3D structure has a positive effect towards improving the cycling performance of LFP. When the current density is increased to $2 \mathrm{~mA} \mathrm{~cm}^{-2}$ based on the area of anode (corresponding to about $7 \mathrm{C}$ for the LFP cathode), the LFP/Li-NGNF full cell still can exhibit a stable cycling performance. The charge/discharge voltage profiles at different cycles (Figure 6a-c) clearly demonstrate that the LFP/Li-NGNF full cell has the highest capacity retention among them, indicating that Li-NGNF is beneficial for stable capacity of the LFP cathode. The capacity increase during the early stage of cycling for the LFP/Li-NGNF full cell is attributed to the activation process in the LFP materials at high current density, and this phenomenon has also been observed by other groups. ${ }^{[7,22]}$ The polarization of the LFP/LiNGNF full cell between the charge and discharge profiles appears nearly constant after 50 cycles, suggesting unvarying charge transfer resistance, which is helpful for maintaining the stability of cells during long-term cycling. Even over 500 cycles, the LFP/Li-NGNF full cell still can maintain a reversible capacity of $94.1 \mathrm{mAh} \mathrm{g}^{-1}$ with a Coulombic efficiency of nearly $100.0 \%$, while the cells with Li-NF electrode exhibit a reversible capacity of $49.5 \mathrm{mAh} \mathrm{g}^{-1}$ after 400 cycles. As a reference, the reversible capacity of the LFP/Li-Cu full cell drops down to below $30 \mathrm{mAh} \mathrm{g}^{-1}$ after only 75 cycles (Figure $\mathbf{6 d}$ ). The above results confirm that there is less Li loss on the Li-NGNF anode in a LFP full cell compared with Li-NF anode and Li-Cu anode, 


\section{WILEY-VCH}

especially when the electrodes are tested under high current density, which is in agreement with the results from half cells (Figure 4).

The stability of the interfacial charge transfer process was further analyzed by EIS (Figure 6e-g), which is helpful to understand the reasons why the LFP/Li-NGNF full cell can maintain stable cycling performance based on the electrochemistry. Compared to the $1^{\text {st }}$ cycle, the highfrequency semicircle of LFP/Li-Cu is clearly increased after 50 cycles, indicating that the Li$\mathrm{Cu}$ anode has an unstable surface. This is due to the 3D host structure of the Li-NGNF and Li$\mathrm{NF}$ anodes, which could decrease the effective current density and relieve the large volume changes during Li plating/stripping, leading to more uniform Li deposition and a stable SEI film. Therefore, the diameters of the semicircles for LFP/Li-NGNF and LFP/Li-NF full cells are much more stable than for $\mathrm{LFP} / \mathrm{Li}-\mathrm{Cu}$. Whether for the fresh cells or the cells after many cycles, the Nyquist plots show that the LFP/Li-NGNF full cell possesses smaller polarization resistance than that of LFP/Li-NF owing to the better conductivity and lithiophilicity of NG. In addition, compared with the control sample of NF, the NGNF provides better wettability of the electrode by the electrolyte (Figure S8). In fact, apart from the room-temperature electrical performance, the low-temperature electrochemical performance is also very important, because cell performance can change dramatically with a decrease in temperature. As shown in Figure S9, the LFP/Li-NGNF full cell also delivers good electrochemical performance at a low temperature of $-10{ }^{\circ} \mathrm{C}$, which is highly promising for future practical applications in a cold environment.

\section{Conclusions}




\section{WILEY-VCH}

In summary, a NGNF hybrid matrix was investigated as a stable 3D host for Li metal anode. One the hand, this hybrid anode has the features of a common 3D electrode, which could greatly decrease the effective current density through its high surface area and relieve the huge volume changes owing to its open porous structure. On the other hand, NG with lithiophilic functional groups (such as pyridinic $\mathrm{N}$, pyrrolic $\mathrm{N}$, and pyridine- $\mathrm{N}$ oxides) can decrease the Li nucleation overpotential, store a certain amount of Li via the conventional intercalation mechanism, and guide uniform Li plating/stripping. Therefore, the 3D NGNF hybrid electrode exhibits excellent cycling performance by combining the advantages of 3D electrode and NG with lithiophilic functional groups. Even when the current density is increased to as high as $2 \mathrm{~mA} \mathrm{~cm}^{-2}$, the $3 \mathrm{D}$ NGNF hybrid anode can maintain a low and stable voltage hysteresis of $67 \mathrm{mV}$, and the Coulombic efficiency of Li plating/stripping can remain as high as $98.3 \%$ for more than 200 cycles. The potential application of this hybrid anode is further demonstrated by assembling full cells with LFP as cathode. The LFP/Li-NGNF full cell delivers the best cycling performance, lowest combined resistance, and smallest polarization among the full cell samples, indicating its good practical prospects. In addition, the LFP/Li-NGNF full cell also exhibits excellent electrochemical performance in a low working temperature environment.

\section{Experimental Section}

Material Synthesis: The 3D NGNF composites were prepared by a simple hydrothermal method. Firstly, commercial graphene oxide (GO) solution with a concentration of $4 \mathrm{mg} / \mathrm{ml}$ was subjected to sonication for $1 \mathrm{~h}$ in order to obtain well-dispersed GO solution. The cleaned NF was immersed in the above GO solution and centrifuged at $500 \mathrm{rpm}$ for $15 \mathrm{~min}$. After removing excess GO solution from the surface of NF with filter paper, the obtained samples were dried 


\section{WILEY-VCH}

under vacuum. Then, the above process was repeated two times. Subsequently, the synthesized samples were immersed in a solution of $20 \mathrm{ml}$ water and $176 \mu \mathrm{l}$ ammonia and sealed in a 50 $\mathrm{mL}$ Teflon autoclave, which was then kept in an oven at $160{ }^{\circ} \mathrm{C}$ for $4 \mathrm{~h}$. Finally, the resulting materials were washed with distilled water several times, followed by drying at $80^{\circ} \mathrm{C}$ for $12 \mathrm{~h}$ under vacuum.

Structural Characterizations: The morphology and element distribution of samples were characterized by using a scanning electron microscopy (SEM, Hitachi SU8000, Japan) coupled with an energy dispersive X-ray spectrometer (EDS). Raman spectroscopy (Renishaw InVia Confocal Micro-Raman spectrometer with a laser wavelength of $532 \mathrm{~nm}$ ) was employed to characterize the graphene in the NGNF. X-ray photoelectron spectroscopy (XPS) was conducted using an ESCALAB 250Xi system X-ray photoelectron spectrometer.

Electrochemical Measurements: CR2025 half coin cells with NGNF, NF, or $\mathrm{Cu}$ foil as the working electrode and Li metal as the counter electrode were assembled in an argon-filled glove box for Li deposition/stripping testing. Before assembly, NGNF and NF wre pressed from 1.5 $\mathrm{mm}$ down to about $1.1 \mathrm{~mm}$ thick. The electrolyte was $1 \mathrm{M}$ lithium bis(trifluoromethanesulfonyl)imide (LiTFSI) in a mixed solvent of 1,3-dioxolane (DOL) and 1,2-dimethoxyethane (DME) $(1: 1, \mathrm{~V} / \mathrm{V})$ with the addition of $1 \mathrm{wt} . \% \mathrm{LiNO}_{3}$. To standardize the testing, $70 \mu \mathrm{L}$ of the above electrolyte was used for all the half coin cells. The half coin cells with NGNF were first cycled at $0.01-1 \mathrm{~V}$ for four cycles to stabilize the SEI and remove the surface contamination. For the Coulombic efficiency test at different current densities $(0.5,1.0$, and $2.0 \mathrm{~mA} \mathrm{~cm}$ ), the Li deposition capacity was fixed at $1.0 \mathrm{mAh} \mathrm{cm}^{-2}$, and the cut-off potential for the stripping process was set to $1.0 \mathrm{~V}$. The Coulombic efficiency is defined as the 


\section{WILEY-VCH}

ratio of the charge capacity to the discharge capacity. For LFP full cells, the Li-NGNF anodes were obtained from preprocessed half cells (with $10 \mathrm{mAh} \mathrm{cm}^{-2}$ deposited on the NGNF electrode at a current density of $0.5 \mathrm{~mA} \mathrm{~cm}^{-2}$ ). Similarly, Li-NF and Li-Cu control anodes were obtained using the same method. To fabricate LFP cathode for the full cell testing, LFP powders (Likai Co. Ltd., Taiwan) were mixed with carbon black and polyvinylidene fluoride (PVDF) in a weight ratio of 8:1:1 with N-methyl-2-pyrrolidone as the solvent. The areal mass loading of LFP cathode was about $1.6-1.8 \mathrm{mg} \mathrm{cm}^{-2}$, and the electrolyte employed in the LFP full cells was 1.0 M lithium hexafluorophosphate $\left(\mathrm{LiPF}_{6}\right)$ in ethylene carbonate /diethyl carbonate $(1: 1, \mathrm{~V} / \mathrm{V})$. All the LFP full cells were tested using a Neware Battery Testing System within the voltage range of $2.5-4.2 \mathrm{~V}$ at room temperature or low temperature $\left(-10{ }^{\circ} \mathrm{C}\right)$. Electrochemical impedance spectroscopy was conducted over a frequency range of $100 \mathrm{kHz}$ to $100 \mathrm{mHz}$, and the amplitude was set to $10 \mathrm{mV}$.

Theoretical calculations: Calculations were performed by using the Vienna ab initio simulation package (VASP). The projector augmented wave (PAW) technique and the Perdew-BurkeErnzerhof functional with a generalized gradient approximation form (GGA-PBE) were adopted to treat the exchange correlation energy. ${ }^{[23]}$ The sampling over the Brillouin zone was conducted using a $3 \times 3 \times 1$ Monkhorst-Pack mesh. The plane-wave energy cut-off was set to 500 eV. For the geometry optimization, the conjugate-gradient (CG) algorithm was used, and all the atomic coordinates were fully relaxed. The optimization process was repeated until the total energy change of the system was less than $1.0 \times 10^{-5} \mathrm{eV}$ and the force on each atom was less than $0.03 \mathrm{eV} \cdot \AA^{-1}$. To evaluate the adsorption strength of Li on different surfaces (Figure 1), the adsorption energies $(\mathrm{eV})$ were calculated as, 


\section{WILEY-VCH}

$E_{a d s}=E_{L i / \text { Surf }}-E_{L i}-E_{\text {Surf }}$

Where $E_{L i / S u r f}, E_{L i}$, and $E_{S u r f}$ are the total energies for the Li/surface system, the Li atom, and the relevant surface.

\section{Supporting Information}

Supporting Information is available from the Wiley Online Library or from the author.

\section{Acknowledgements}

Financial support from the National Natural Science Foundation of China (No. 51272051 and No. 51604089), the Fundamental Research Funds for the Central Universities (Grant No. HIT.NSRIF.2017024), the China Postdoctoral Science Foundation (Grant No. 2016M601431), and the Heilongjiang Province Postdoctoral Science Foundation (Grant No. LBH-Z16056) is gratefully acknowledged.

Received: ((will be filled in by the editorial staff))

Revised: ((will be filled in by the editorial staff)) Published online: ((will be filled in by the editorial staff))

\section{References}

[1] N. Nitta, F. Wu, J. T. Lee, G. Yushin, Mater. Today 2015, 18, 252.

[2] a) D. Lin, Y. Liu, Y. Cui, Nat. Nano. 2017, 12, 194; b) W. Xu, J. Wang, F. Ding, X. Chen,

E. Nasybulin, Y. Zhang, J.-G. Zhang, Energy Environ. Sci. 2014, 7, 513.

[3] X.-B. Cheng, R. Zhang, C.-Z. Zhao, F. Wei, J.-G. Zhang, Q. Zhang, Adv. Mater. 2016, 3, 1500213. 


\section{WILEY-VCH}

[4] a) J. Heine, P. Hilbig, X. Qi, P. Niehoff, M. Winter, P. Bieker, J. Electrochem. Soc. 2015, 162, A1094; b) J. Guo, Z. Wen, M. Wu, J. Jin, Y. Liu, Electrochem. Commun. 2015, 51, 59; c)

W. Jia, C. Fan, L. Wang, Q. Wang, M. Zhao, A. Zhou, J. Li, ACS Appl. Mater. Interfaces. 2016, 8, 15399; d) M. Ishikawa, M. Morita, Y. Matsuda, J. Power Sources 1997, 68, 501; e) H. Ye, Y.-X. Yin, S.-F. Zhang, Y. Shi, L. Liu, X.-X. Zeng, R. Wen, Y.-G. Guo, L.-J. Wan, Nano Energy 2017, 36, 411.

[5] F. Ding, W. Xu, G. L. Graff, J. Zhang, M. L. Sushko, X. Chen, Y. Shao, M. H. Engelhard, Z. Nie, J. Xiao, X. Liu, P. V. Sushko, J. Liu, J.-G. Zhang, J. Am. Chem. Soc. 2013, 135, 4450.

[6] M. Wu, Z. Wen, Y. Liu, X. Wang, L. Huang, J. Power Sources 2011, 196, 8091.

[7] N.-W. Li, Y.-X. Yin, C.-P. Yang, Y.-G. Guo, Adv. Mater. 2016, 28, 1853.

[8] Y. Liu, D. Lin, P. Y. Yuen, K. Liu, J. Xie, R. H. Dauskardt, Y. Cui, Adv. Mater. 2017, 29, 1605531.

[9] B. Zhu, Y. Jin, X. Hu, Q. Zheng, S. Zhang, Q. Wang, J. Zhu, Adv. Mater. 2017, 29, 1603755.

[10]a) S. S. Chi, Y. C. Liu, W. L. Song, L. Z. Fan, Q. Zhang, Adv. Funct. Mater. 2017, 27, 1700348; b) D. C. Lin, Y. Y. Liu, Z. Liang, H. W. Lee, J. Sun, H. T. Wang, K. Yan, J. Xie, Y. Cui, Nat. Nano. 2016, 11, 626; c) J. Lang, Y. Jin, X. Luo, Z. Liu, J. Song, Y. Long, L. Qi, M. Fang, Z. Li, H. Wu, J. Mater. Chem. A 2017, 5, 19168; d) Z. Liang, D. Lin, J. Zhao, Z. Lu, Y. Liu, C. Liu, Y. Lu, H. Wang, K. Yan, X. Tao, Y. Cui, Proc. Natl. Acad. Sci. 2016, 113, 2862. [11]K. Yan, Z. Lu, H.-W. Lee, F. Xiong, P.-C. Hsu, Y. Li, J. Zhao, S. Chu, Y. Cui, Nat. Energy 2016, $1,16010$.

[12]S. H. Wang, Y. X. Yin, T. T. Zuo, W. Dong, J. Y. Li, J. L. Shi, C. H. Zhang, N. W. Li, C. J. Li, Y. G. Guo, Adv. Mater. 2017, 29, 1703729. 


\section{WILEY-VCH}

[13]R. Zhang, X. R. Chen, X. Chen, X. B. Cheng, X. Q. Zhang, C. Yan, Q. Zhang, Angew. Chem. Int. Ed. Engl. 2017, 56, 7764.

[14] a) H. J. Chang, A. J. Ilott, N. M. Trease, M. Mohammadi, A. Jerschow, C. P. Grey, J. Am. Chem. Soc. 2015, 137, 15209; b) J. Chazalviel, Phys. Rev. A 1990, 42, 7355.

[15]X. B. Cheng, R. Zhang, C. Z. Zhao, Q. Zhang, Chem. Rev. 2017, 117, 10403.

[16]D. Kuang, L. Xu, L. Liu, W. Hu, Y. Wu, Appl. Surf. Sci. 2013, 273, 484.

[17]D. Long, W. Li, L. Ling, J. Miyawaki, I. Mochida, S.-H. Yoon, Langmuir 2010, 26, 16096.

[18]X.-B. Cheng, T.-Z. Hou, R. Zhang, H.-J. Peng, C.-Z. Zhao, J.-Q. Huang, Q. Zhang, Adv. Mater. 2016, 28, 2888.

[19]P. Zou, Y. Wang, S.-W. Chiang, X. Wang, F. Kang, C. Yang, Nat. Commun. 2018, 9, 464. [20] a) H. Wang, D. Lin, Y. Liu, Y. Li, Y. Cui, Sci. Adv. 2017, 3; b) S. F. Liu, X. H. Xia, Y. Zhong, S. J. Deng, Z. J. Yao, L. Y. Zhang, X. B. Cheng, X. L. Wang, Q. Zhang, J. P. Tu, Adv. Energy Mater. 2018, 8, 1702322.

[21]E. Yoo, J. Kim, E. Hosono, H.-S. Zhou, T. Kudo, I. Honma, Nano Lett. 2008, 8, 2277.

[22] J. Popovic, R. Demir-Cakan, J. Tornow, M. Morcrette, D. S. Su, R. Schlögl, M. Antonietti, M.-M. Titirici, Small 2011, 7, 1127.

[23] a) J. P. Perdew, K. Burke, M. Ernzerhof, Phys. Rev. Lett. 1996, 77, 3865; b) B. Wang, T. Liu, A. Liu, G. Liu, L. Wang, T. Gao, D. Wang, X. S. Zhao, Adv. Energy Mater. 2016, 6, 1600426; c) B. Wang, Y. Xie, T. Liu, H. Luo, B. Wang, C. H. Wang, L. Wang, D. L. Wang, S. X. Dou, Y. Zhou, Nano Energy 2017, 42, 363. 


\section{WILEY-VCH}

Cu foil

Li plating

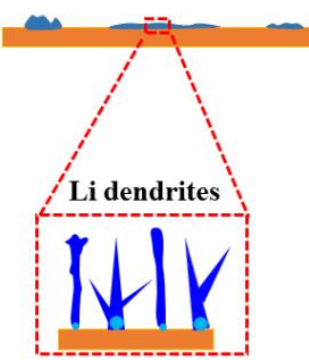

(a)

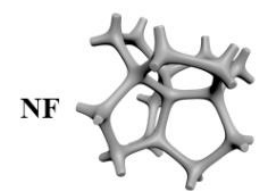

1 Li plating

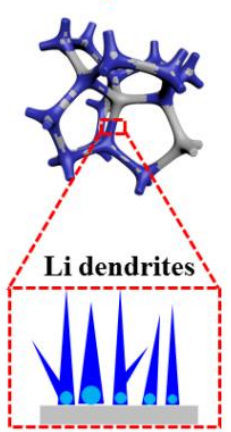

(b)

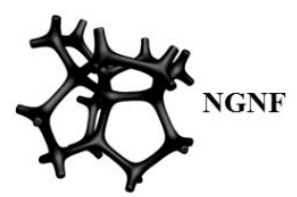

Li plating

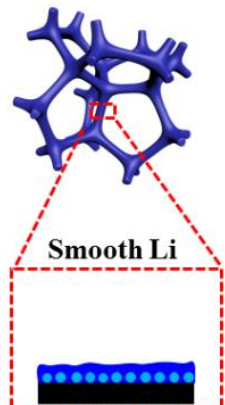

(c)

Scheme 1. Schematic illustration of Li deposition on a) 2D Cu foil, b) 3D NF, and c) 3D NGNF electrode. Due to the large surface area provided by the 3D NF structure and strong binding affinity of Li atoms with lithiophilic functional groups of graphene, stable Li deposition is obtained for NGNF electrode. 


\section{WILEY-VCH}
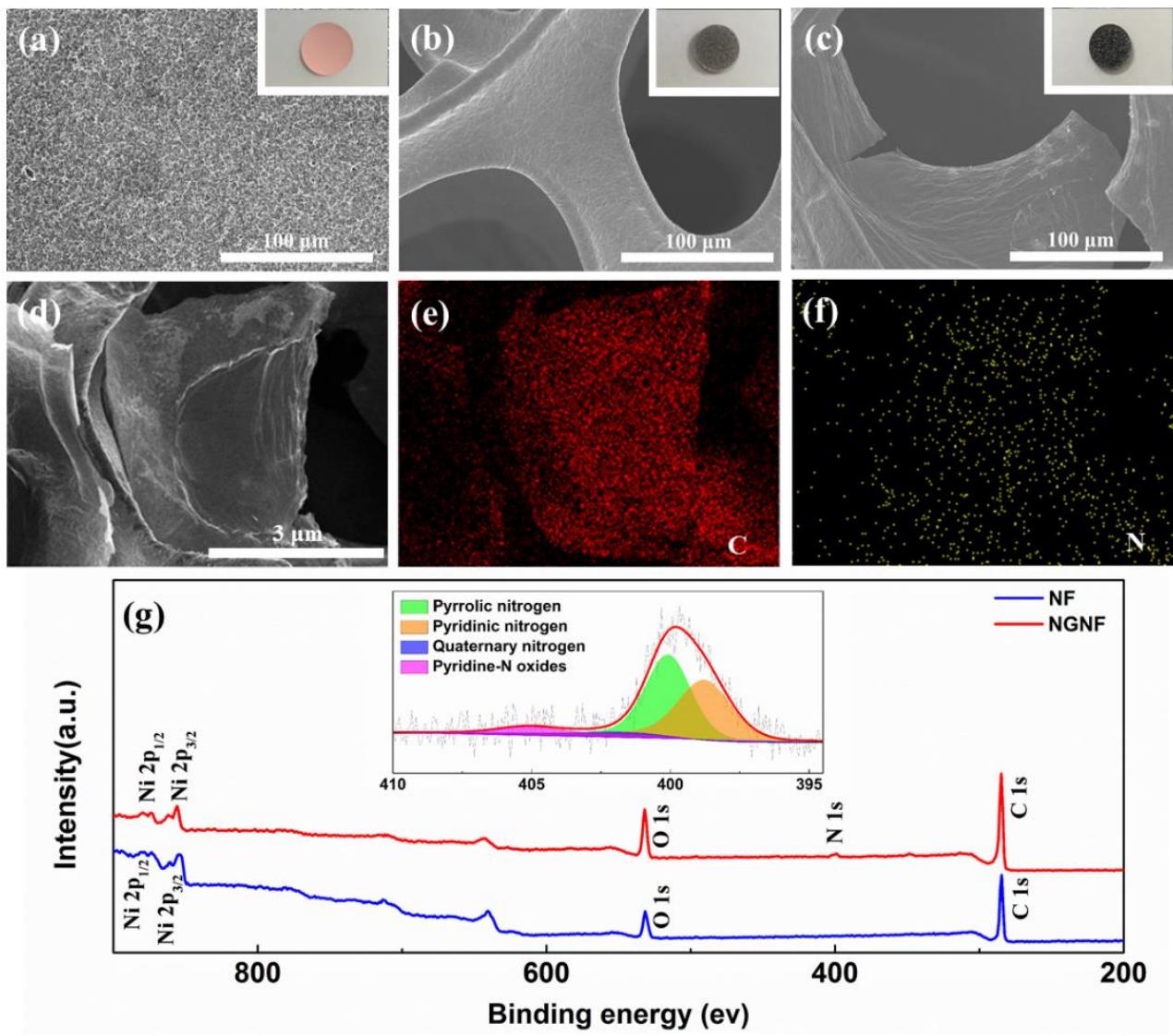

Figure 1. Scanning electron microscope (SEM) images of a) bare $\mathrm{Cu}$ foil, b) NF electrode, and c) NGNF electrode; the insets are their corresponding digital photographs, with each electrode having a the diameter of $14 \mathrm{~mm}$. d-f) SEM-EDS characterization of NGNF electrode. g) XPS characterization of the NF and NGNF electrodes, with the inset showing a decovolution of the $\mathrm{N}$ 1s peak. 


\section{WILEY-VCH}

(a)
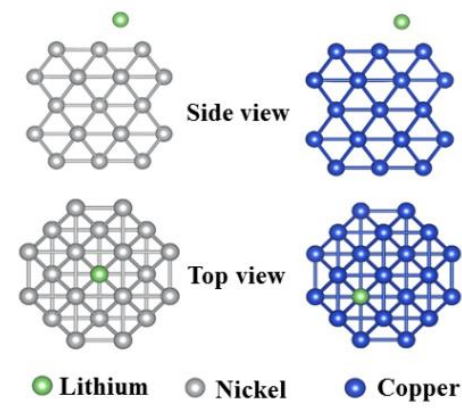

Ni (001) surface $\quad \mathrm{Cu}(001)$ surface

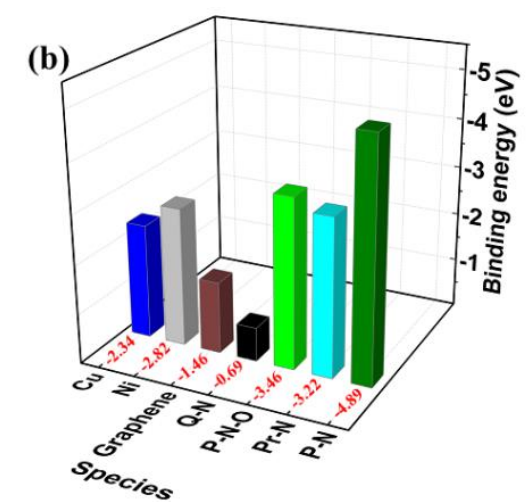

(c) Side view
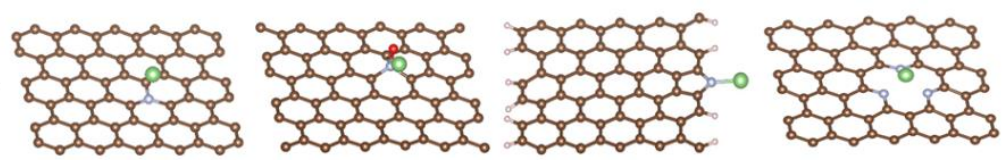

- Carbon

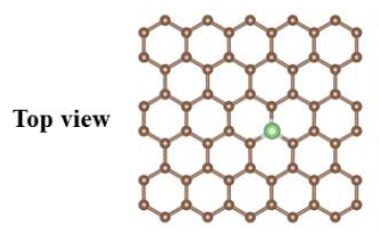

Quaternary N

(Q-N)
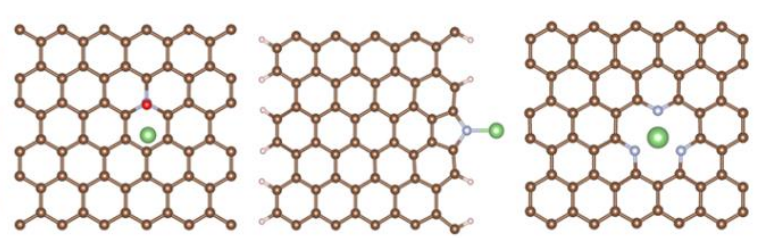

○ Oxygen

Nitrogen

Lithium

(Pr-N)
Pyridine N

(P-N)

Figure 2. Optimized structures of $\mathrm{Li}$ on a) $\mathrm{Ni}, \mathrm{Cu}$, and c) graphene with different $\mathrm{N}$ species. b) Binding energy of a $\mathrm{Li}$ atom with $\mathrm{Cu}, \mathrm{Ni}$, graphene, and graphene with quaternary $\mathrm{N}(\mathrm{Q}-\mathrm{N})$, pyridine-N oxides (P-N-O), pyrrolic $\mathrm{N}(\mathrm{Pr}-\mathrm{N})$, and pyridinic $\mathrm{N}(\mathrm{P}-\mathrm{N})$. 


\section{WILEY-VCH}
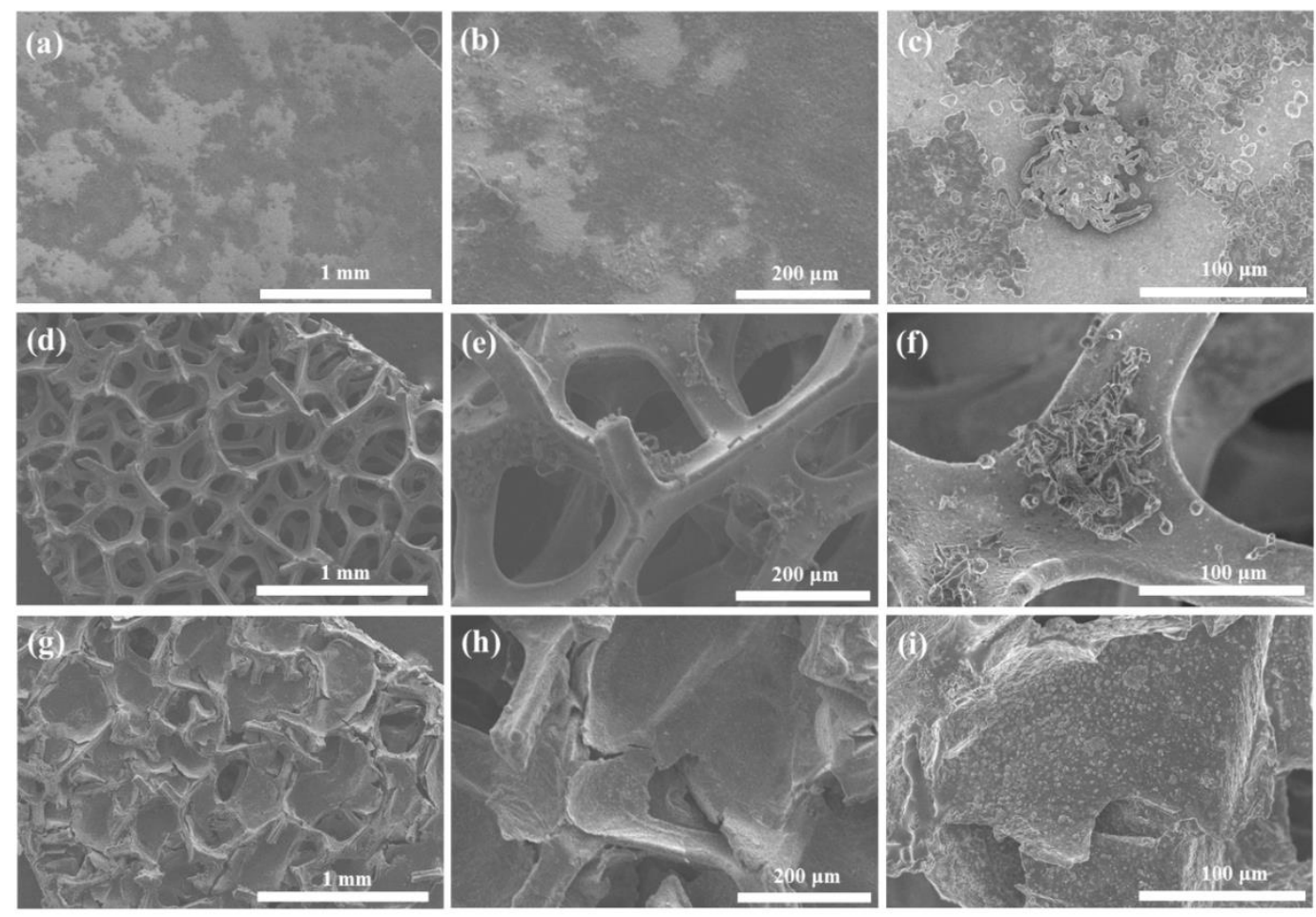

Figure 3. SEM images of $0.5 \mathrm{mAh} \mathrm{cm}^{-2}$ of Li deposited at $0.5 \mathrm{~mA} \mathrm{~cm}^{-2}$ on a-c) bare $\mathrm{Cu}$ electrode, d-f) NF electrode, and g-i) NGNF electrode. 


\section{WILEY-VCH}
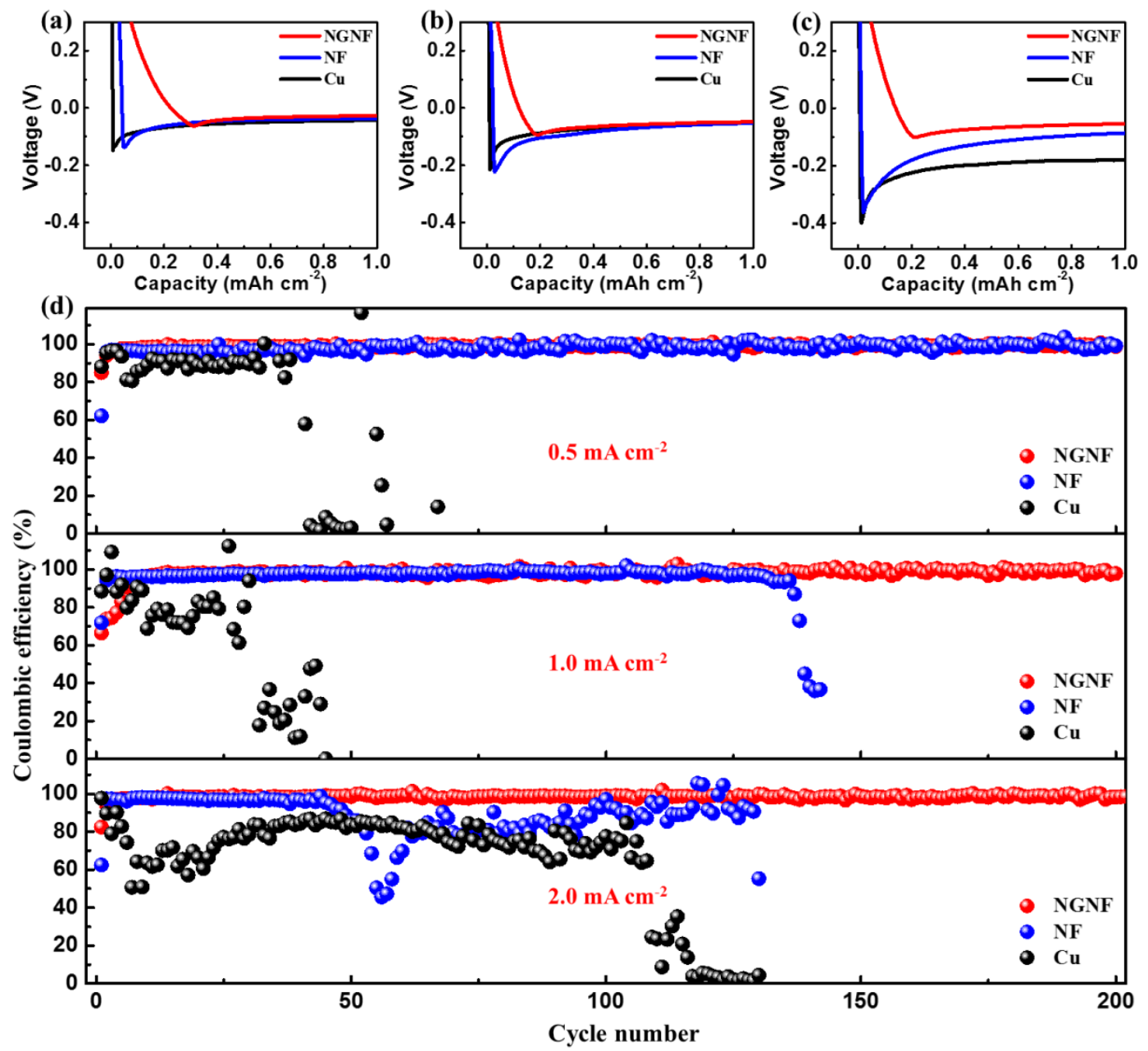

Figure 4. Voltage-capacity curves on various substrates during Li nucleation at a current density of a) $0.5 \mathrm{~mA} \mathrm{~cm}^{-2}$, b) $1.0 \mathrm{~mA} \mathrm{~cm}^{-2}$, and c) $2.0 \mathrm{~mA} \mathrm{~cm}^{-2}$. d) Coulombic efficiency of bare $\mathrm{Cu}$ electrode, NF electrode, and NGNF electrode over 200 cycles with a cycling capacity of 1.0 $\mathrm{mAh} \mathrm{cm}$ at $0.5 \mathrm{~mA} \mathrm{~cm}^{-2}, 1.0 \mathrm{~mA} \mathrm{~cm}^{-2}$, and $2.0 \mathrm{~mA} \mathrm{~cm}^{-2}$, respectively. 


\section{WILEY-VCH}
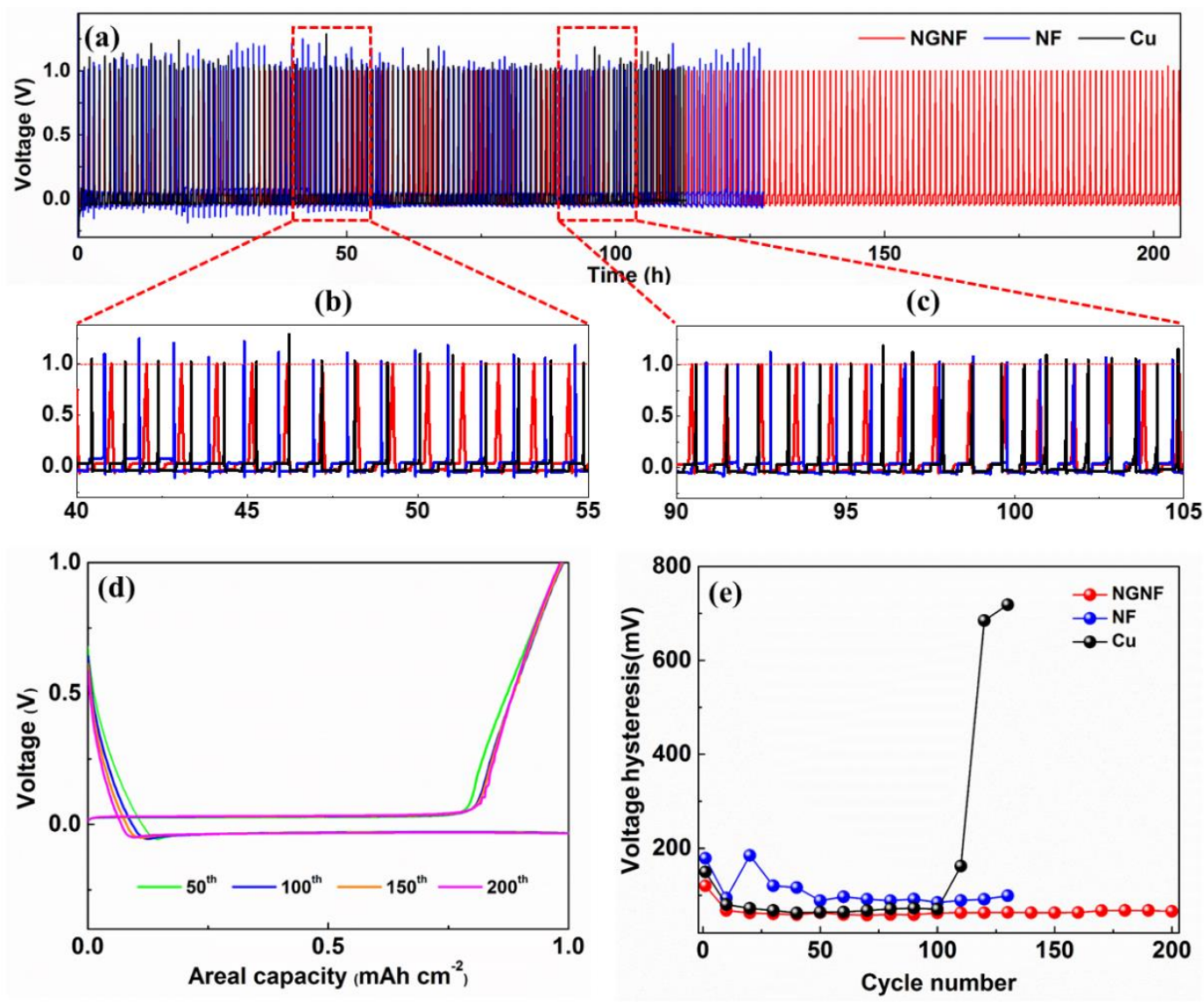

Figure 5. a-c) Voltage-time curves of $\mathrm{Cu}, \mathrm{NF}$, and NGNF electrode at a cycling current density of $2.0 \mathrm{~mA} \mathrm{~cm}^{-2}$. d) Voltage profiles of the $50^{\text {th }}, 100^{\text {th }}, 150^{\text {th }}$, and $200^{\text {th }}$ cycle of NGNF electrode with a cycling capacity of $1.0 \mathrm{mAh} \mathrm{cm}^{-2}$ at $2.0 \mathrm{~mA} \mathrm{~cm}^{-2}$. e) The voltage hysteresis of cells with different electrodes at a current density of $2.0 \mathrm{~mA} \mathrm{~cm}^{-2}$. 
WILEY-VCH
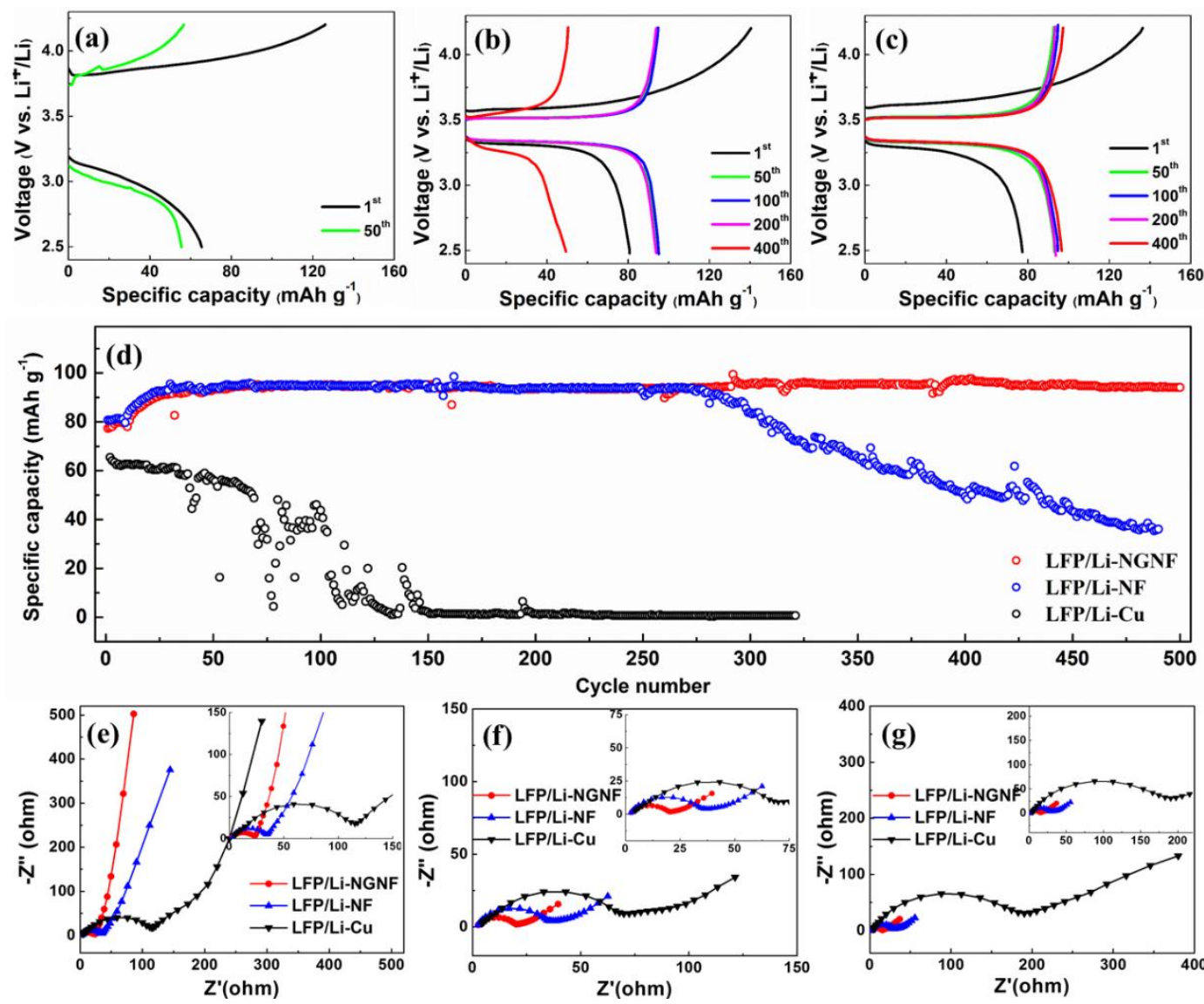

Figure 6. Charge/discharge voltage profiles of a) LFP/Li-Cu, b) LFP/Li-NF, and c) LFP/LiNGNF full cells at $2.0 \mathrm{~mA} \mathrm{~cm}{ }^{-2}$ (calculation based on area of anode). d) Cycling performance of $\mathrm{Li}-\mathrm{Cu}, \mathrm{Li}-\mathrm{NF}$, and Li-NGNF anode in full cells with LFP cathode at $2 \mathrm{~mA} \mathrm{~cm}^{-2}$ (about $7 \mathrm{C}$ based on mass of LFP cathode). e-g) Nyquist plots of the various full cells a) before cycling, $b$ ) after the $1^{\text {st }}$ cycle, and c) $50^{\text {th }}$ cycle, with the insets showing enlargements of the indicated ranges. 


\section{WILEY-VCH}

The table of contents entry should be 50-60 words long, and the first phrase should be bold.

3D lithiophilic N-doped graphene/nickel foam (NGNF) scaffold has been successfully prepared to host $\mathrm{Li}$ by a simple hydrothermal method, which could improve the poor lithiophilicity of nickel foam (NF) due to the N-doped graphene (NG) with lithiophilic functional groups (pyridinic $\mathrm{N}$, pyrrolic $\mathrm{N}$, and pyridine-N oxides), while maintaining its 3D porous electrode structure, leading to uniform Li plating/stripping.

\section{Keyword}

nickel foam, N-doped graphene, Li plating/stripping, Coulombic efficiency, electrochemical performance

Title ((no stars))

Facile Transformation of Non-lithiophilic Nickel Foam into 3D Lithiophilic Scaffold for Stable Lithium Metal Battery

ToC figure ((Please choose one size: $55 \mathrm{~mm}$ broad $\times 50 \mathrm{~mm}$ high or $110 \mathrm{~mm}$ broad $\times 20 \mathrm{~mm}$ high. Please do not use any other dimensions))

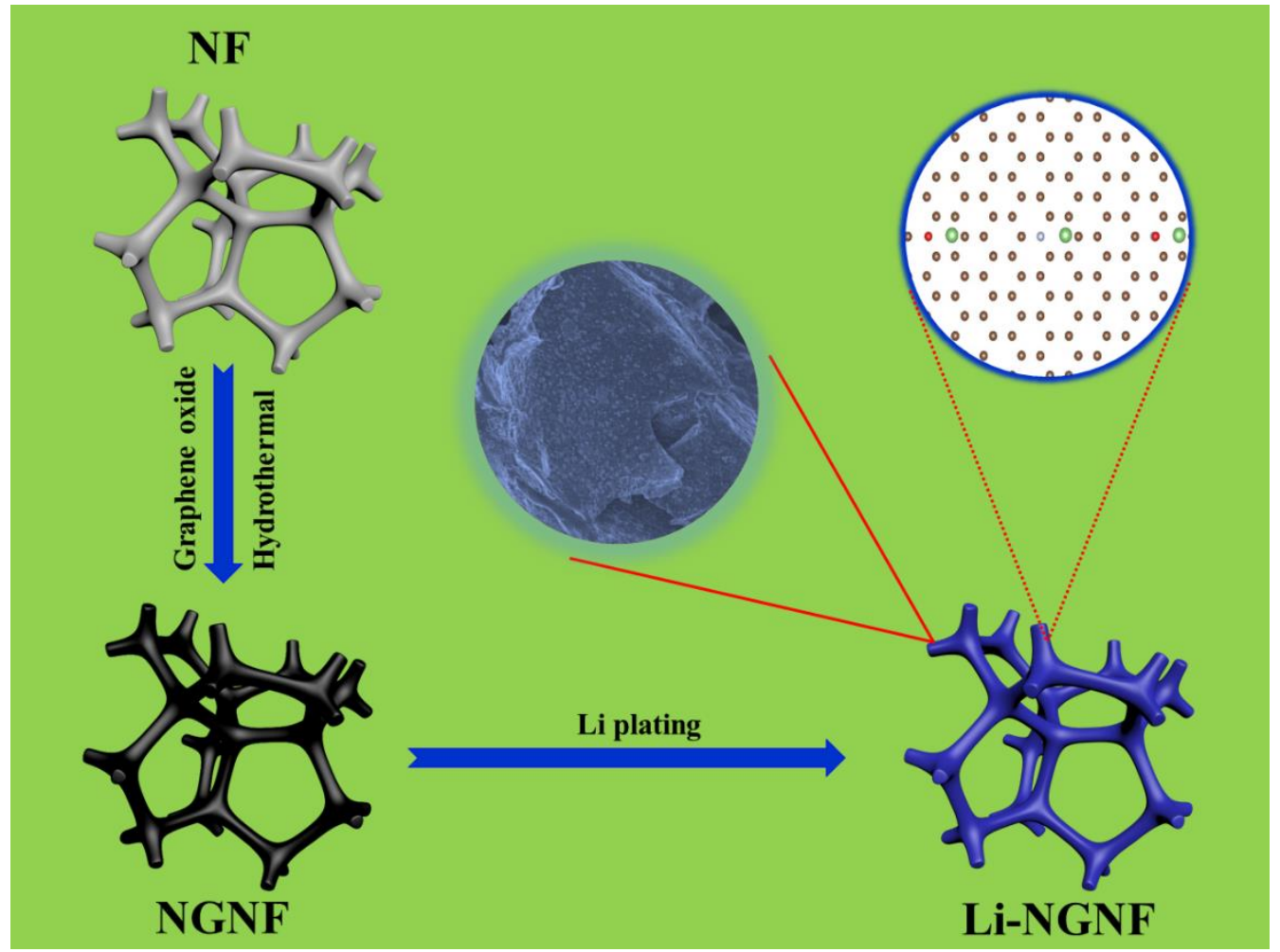

size: $55 \mathrm{~mm}$ broad $\times 50 \mathrm{~mm}$ high 


\section{WILEY-VCH}

Copyright WILEY-VCH Verlag GmbH \& Co. KGaA, 69469 Weinheim, Germany, 2016.

\section{Supporting Information}

Facile Transformation of Non-lithiophilic Nickel Foam into 3D Lithiophilic Scaffold for Stable Lithium Metal Battery

Rensheng Song, Bo Wang*, Ying Xie*, Tingting Ruan, Fei Wang, Ye Yuan, Dianlong Wang* and Shixue Dou* 


\section{WILEY-VCH}

\section{Figures}

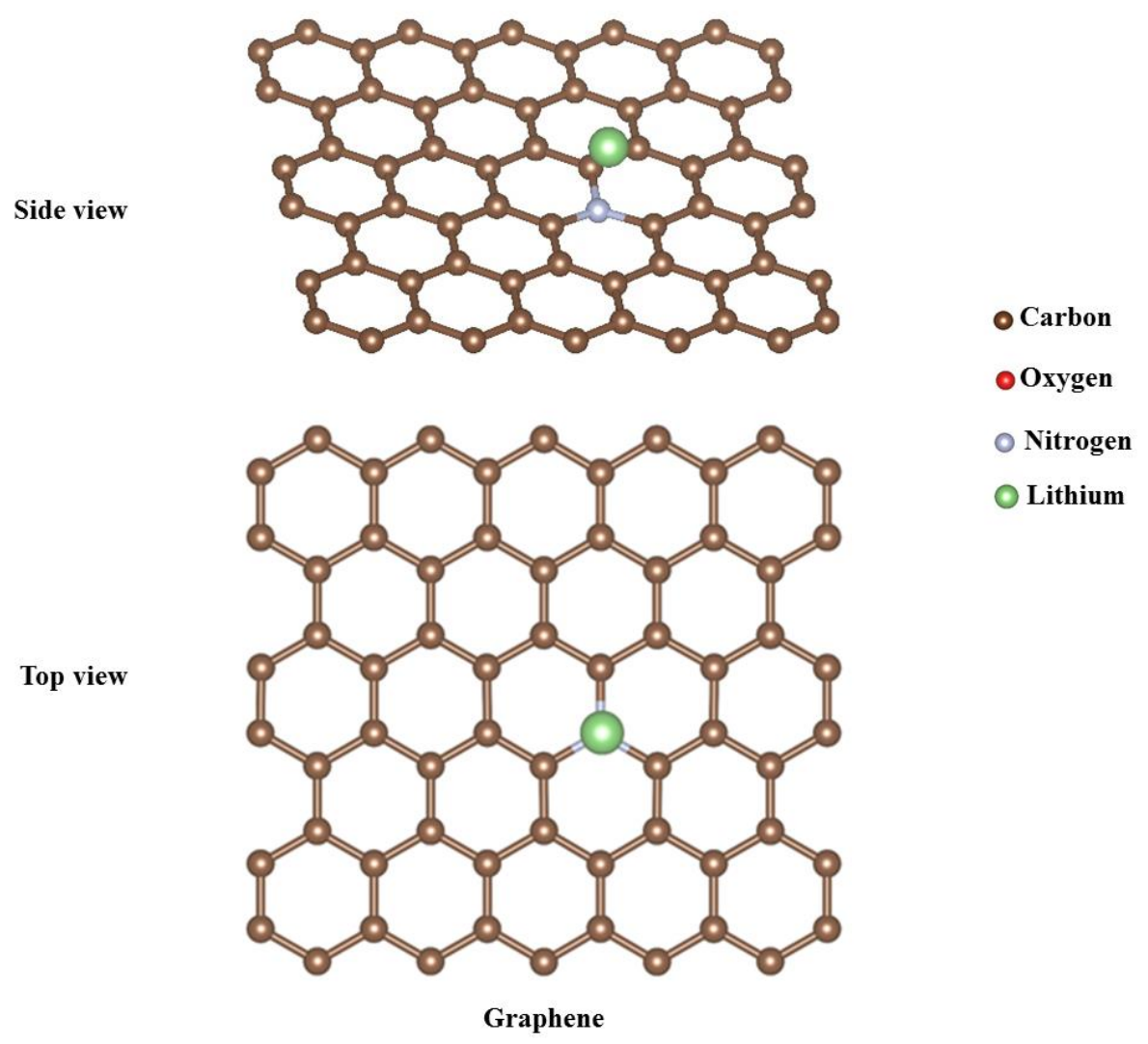

Figure S1. Optimized structure of Li on ideal graphene. 


\section{WILEY-VCH}

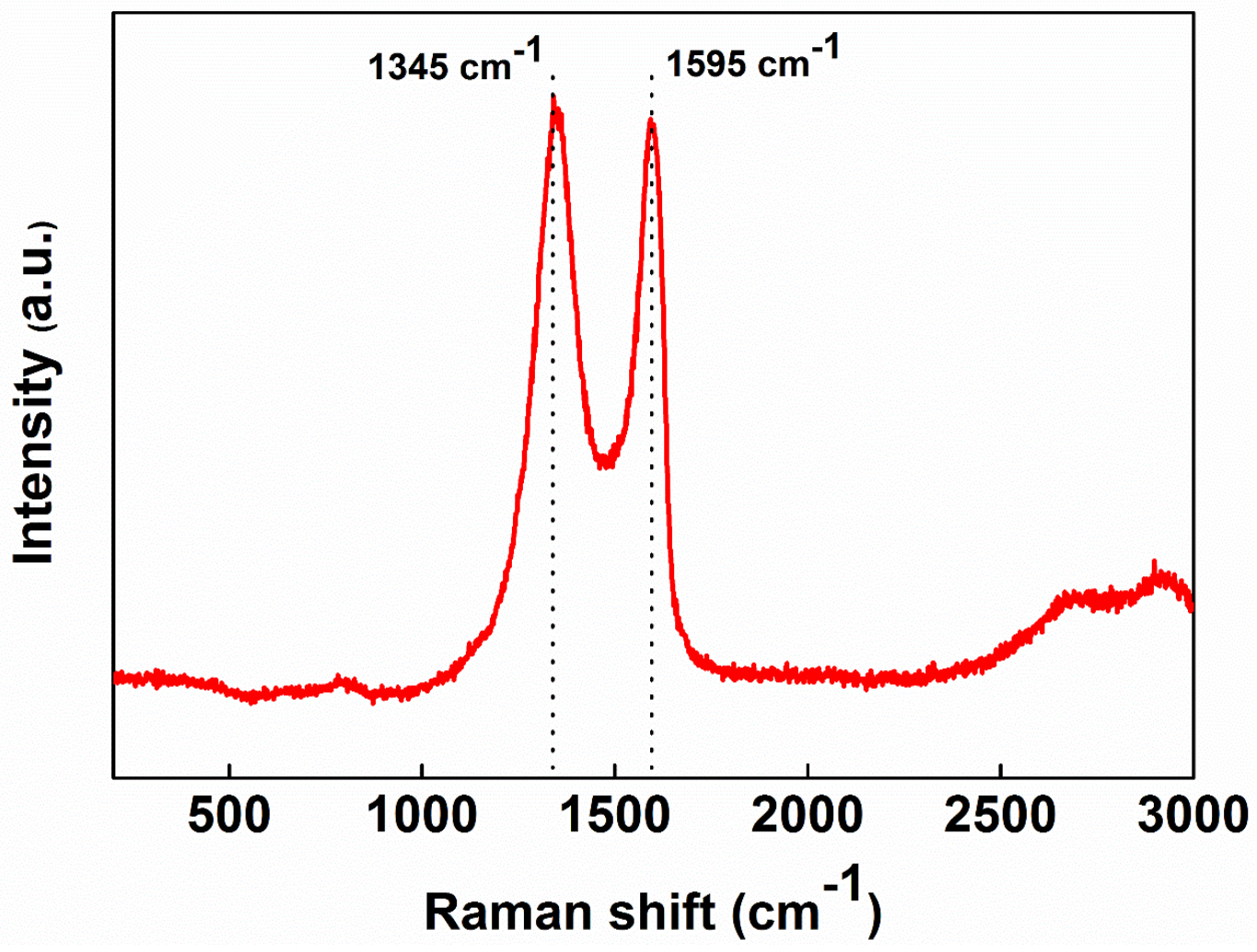

Figure S2. Raman spectrum of NGNF electrode. 


\section{WILEY-VCH}
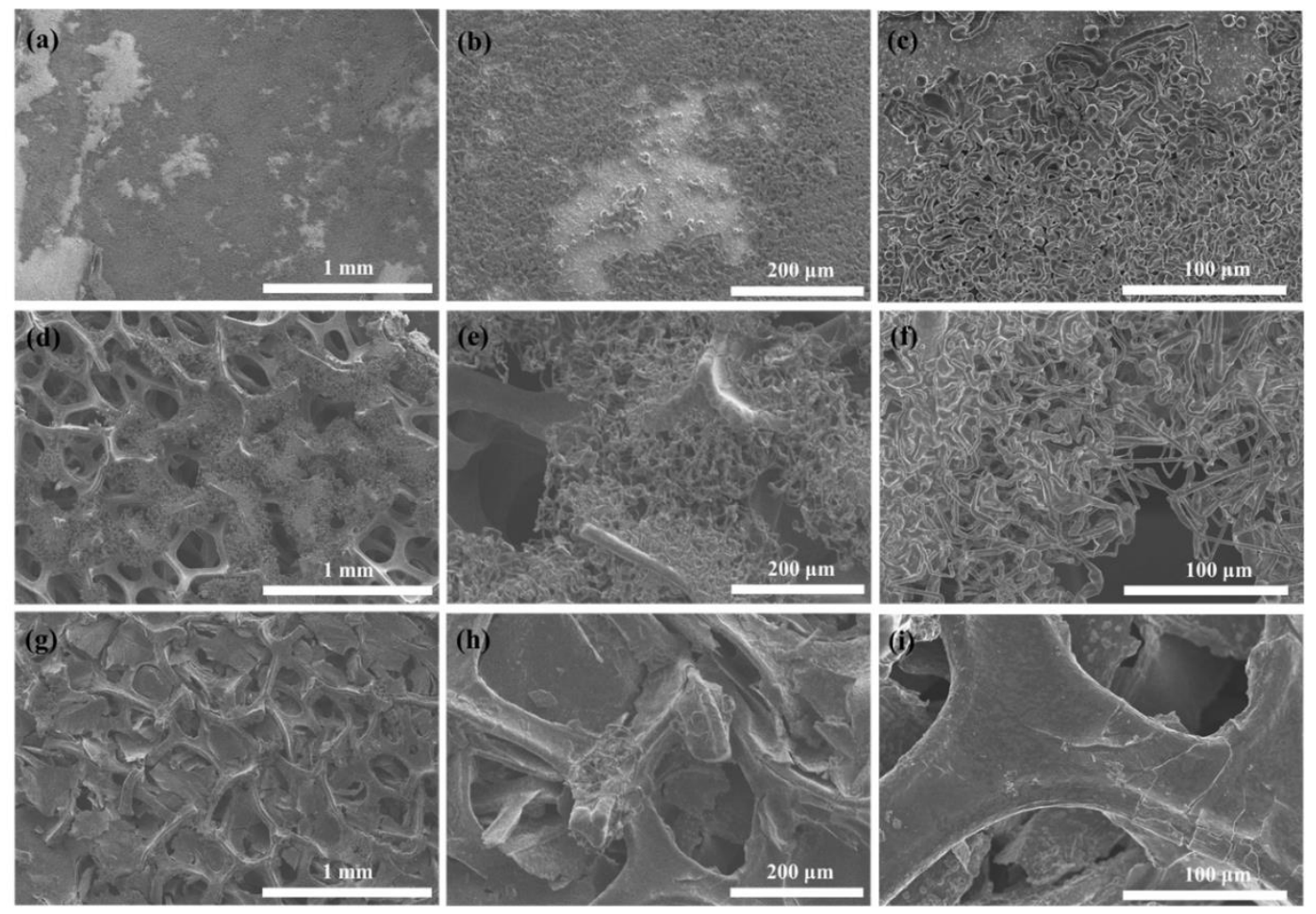

Figure S3. SEM images of $1.0 \mathrm{mAh} \mathrm{cm}^{-2}$ of Li deposited at $0.5 \mathrm{~mA} \mathrm{~cm}{ }^{-2}$ on a-c) bare $\mathrm{Cu}$ electrode, d-f) NF electrode, and g-i) 3D NGNF electrode. 


\section{WILEY-VCH}
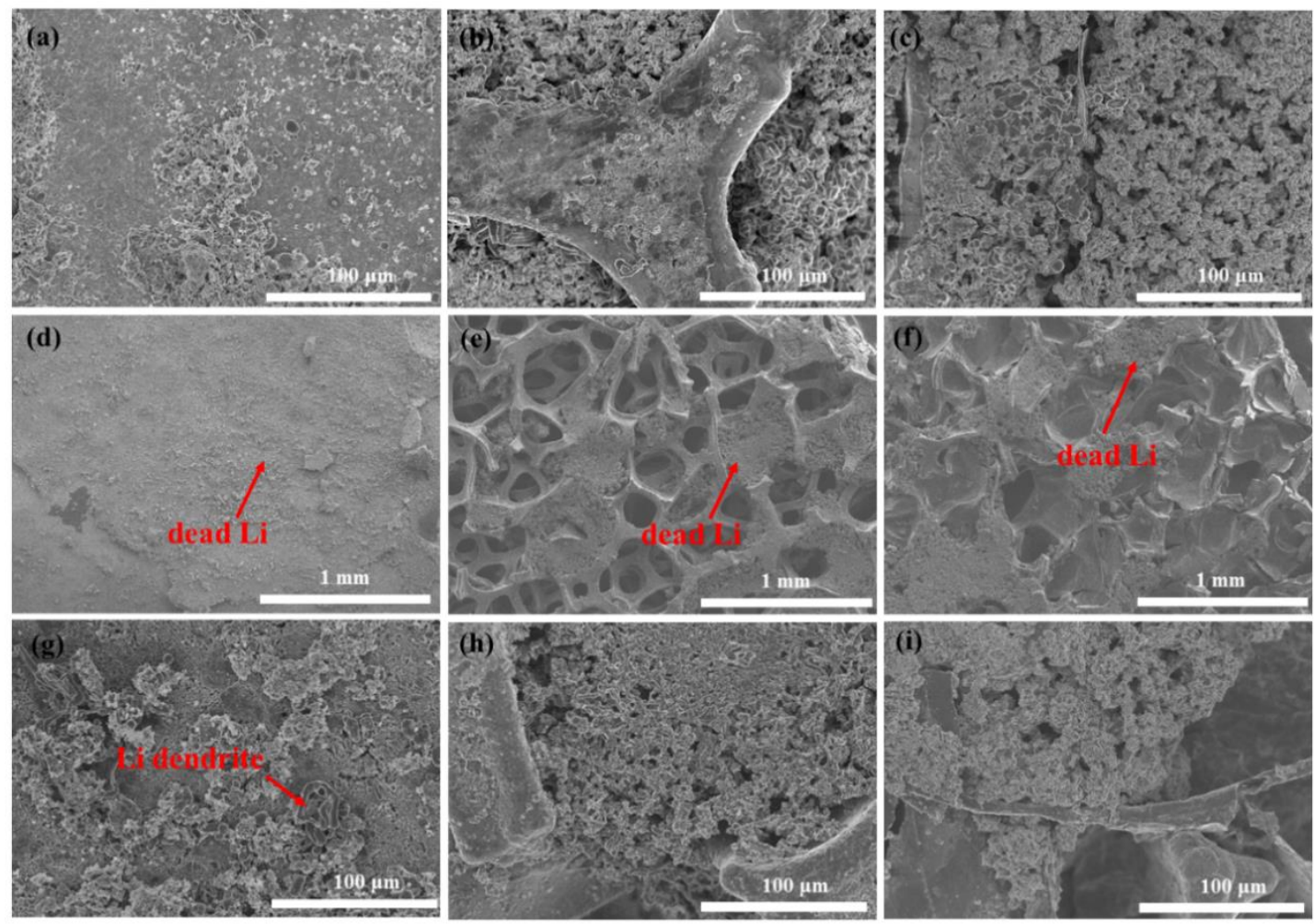

Figure S4. SEM images of $1.0 \mathrm{mAh} \mathrm{cm}^{-2}$ of Li deposited at $1.0 \mathrm{~mA} \mathrm{~cm}^{-2}$ current density on a) bare $\mathrm{Cu}$ electrode, b) NF electrode, and c) NGNF electrode after the $50^{\text {th }} \mathrm{Li}$ plating. The low magnification and high magnification images of $d, g$ ) $\mathrm{Cu}$ electrode, e, h) NF electrode, and f, i) NGNF electrode after the $50^{\text {th }} \mathrm{Li}$ stripping. 


\section{WILEY-VCH}
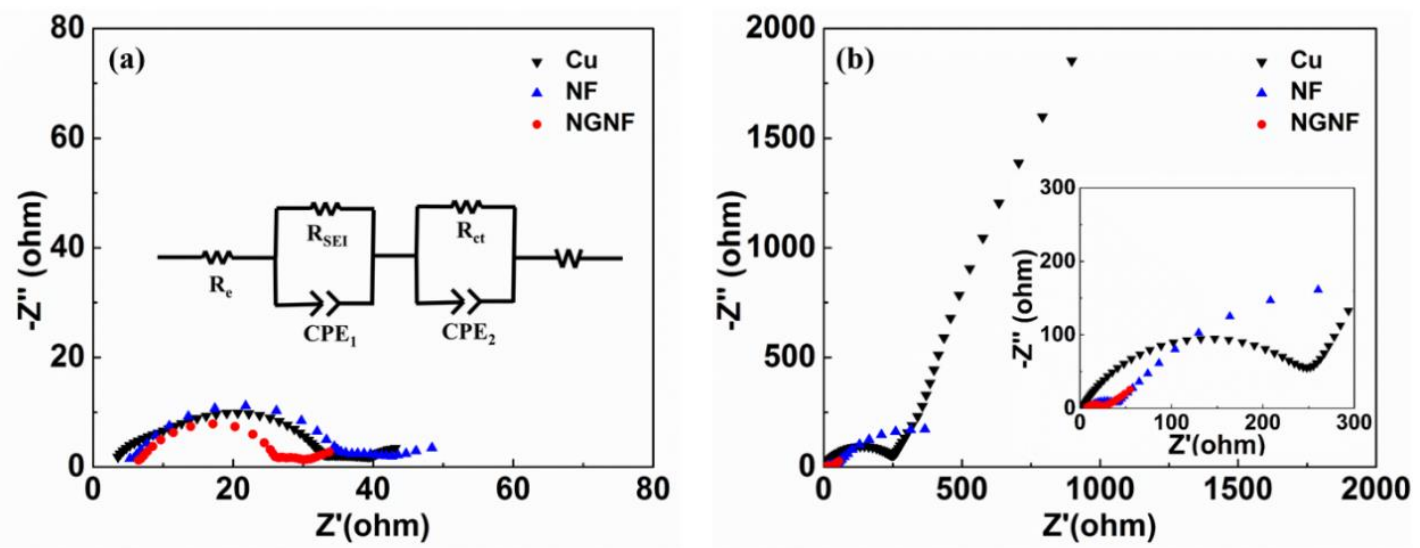

Figure S5. Nyquist plots of the various half cells after the $1^{\text {st }}$ a) plating and b) stripping. The inset of a) is the equivalent circuit used for analysing the results, and the inset of b) is an enlargement of the indicated region. $\mathrm{R}_{\mathrm{e}}, \mathrm{R}_{\mathrm{SEI}}$, and $\mathrm{R}_{\mathrm{ct}}$ are the electrolyte resistance, SEI resistance, and charge transfer resistance, respectively. $\mathrm{W}$ is the Warburg impedance, and $\mathrm{CPE}_{1}$ and $\mathrm{CPE}_{2}$ are constant phase elements reflecting double layer capacitance. 


\section{WILEY-VCH}

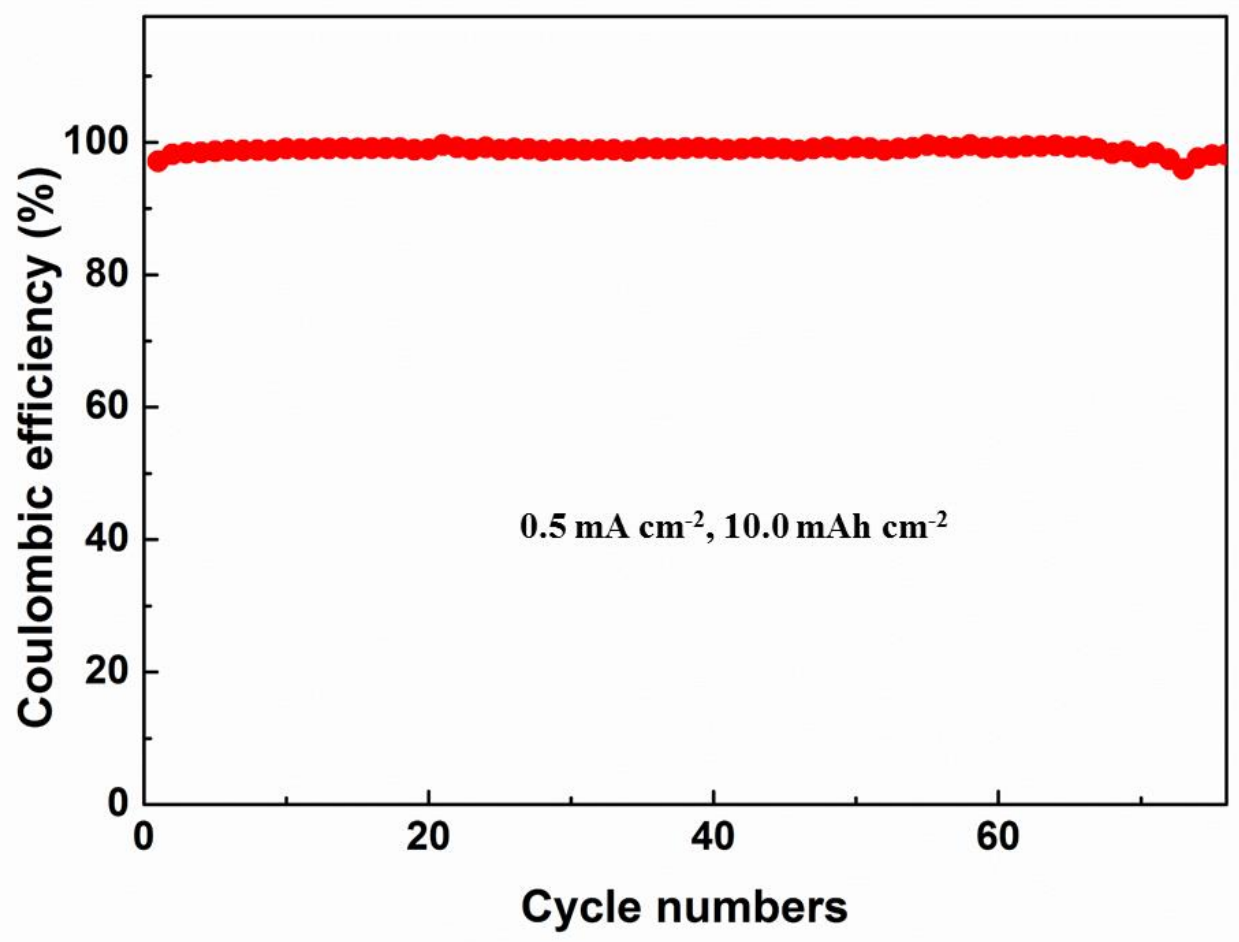

Figure S6. Coulombic efficiency of NGNF electrode with a cycling capacity of $10.0 \mathrm{mAh} \mathrm{\textrm {cm } ^ { - }}$ 2 at a $0.5 \mathrm{~mA} \mathrm{~cm}^{-2}$. 


\section{WILEY-VCH}

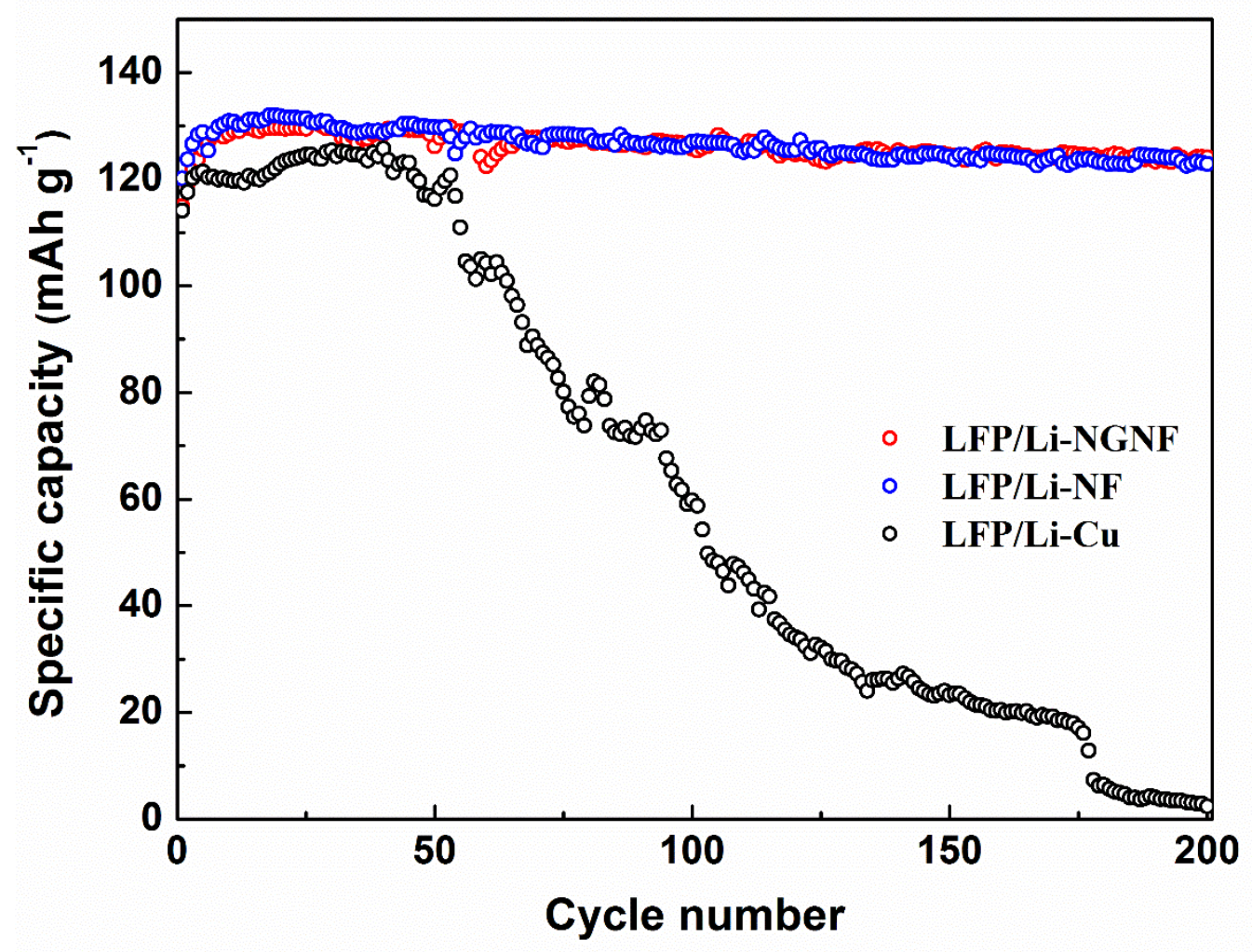

Figure S7. Cycling performances of $\mathrm{Li}-\mathrm{Cu}, \mathrm{Li}-\mathrm{NF}$, and Li-NGNF anode in full cells with LFP cathode at $0.5 \mathrm{~mA} \mathrm{~cm}^{-2}$ (based on Li metal anode). 


\section{WILEY-VCH}

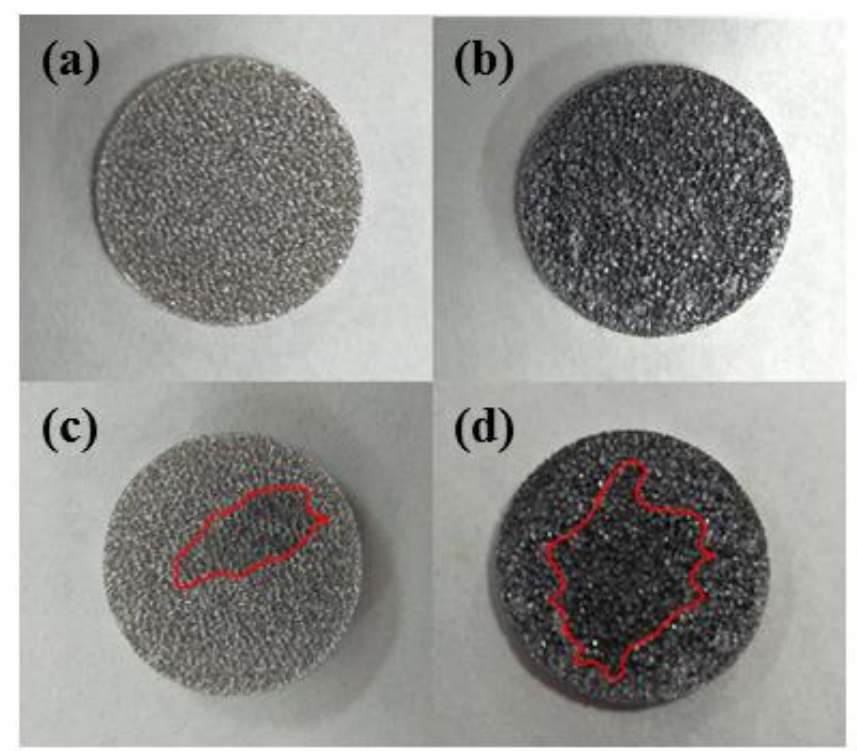

Figure S8. Comparisons of wettability of a, c) NF and b, d) NGNF electrode based on the same $20 \mu \mathrm{L}$ volume of electrolyte. The areas outlined in red correspond to the uptake of electrolyte. 


\section{WILEY-VCH}

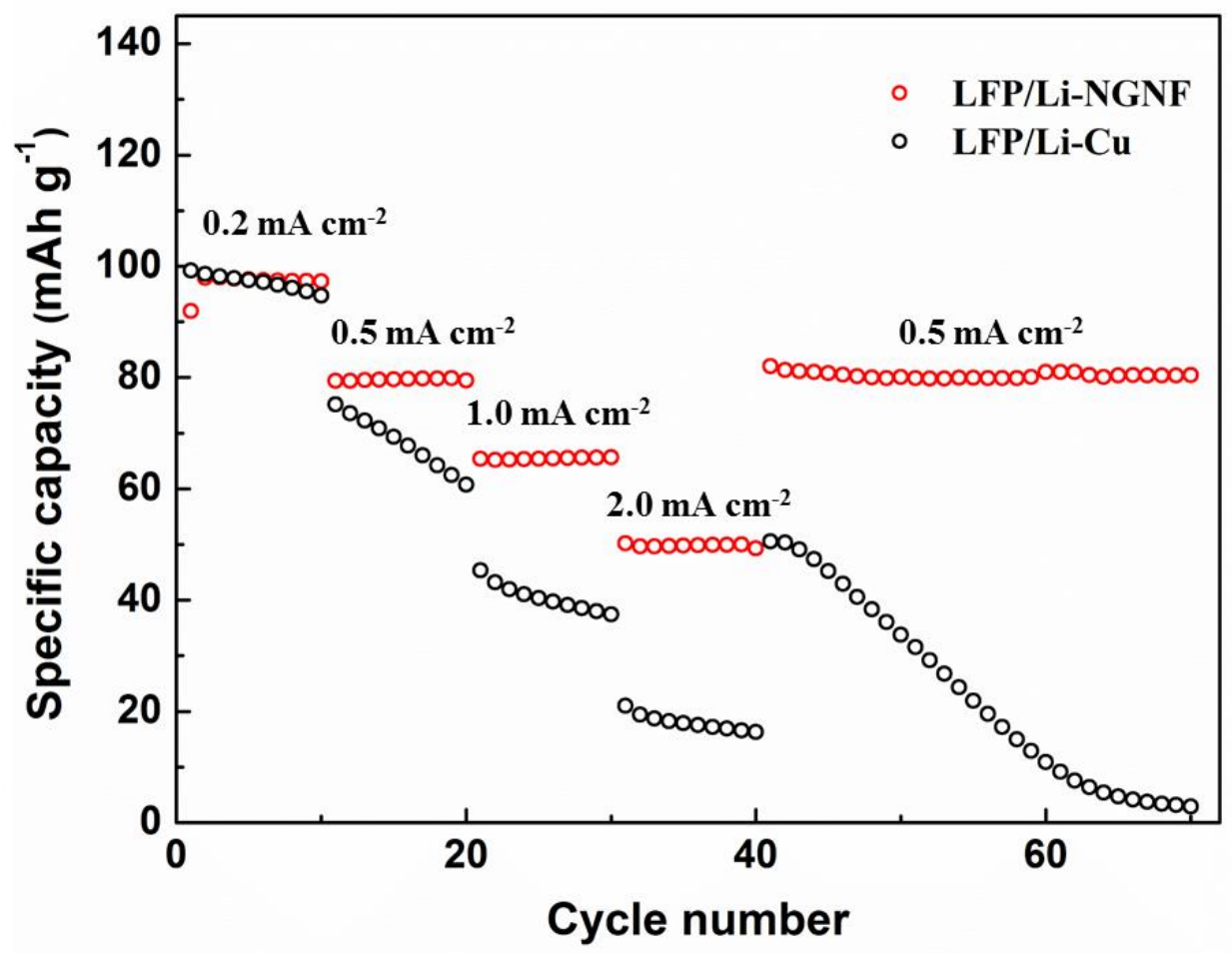

Figure S9. Rate performance of LFP full cells with $\mathrm{Li}-\mathrm{NGNF}$ and $\mathrm{Li}-\mathrm{Cu}$ anodes at low temperature $\left(-10^{\circ} \mathrm{C}\right)$. 